Sharif University of Technology
Scientia Iranica
Transactions E: Industrial Engineering
SCIENTIA

\title{
A novel interval type-2 fuzzy AHP-TOPSIS approach for ranking reviewers in online communities
}

\author{
H. Abbasimehr and M.J. Tarokh* \\ IT Group, Department of Industrial Engineering, K.N. Toosi University of Technology, Tehran, Iran.
}

Received 14 March 2015; received in revised form 4 August 2015; accepted 15 September 2015

\author{
KEYWORDS \\ Customer review; \\ Reviewer credibility; \\ Fuzzy AHP; \\ Interval type-2 fuzzy \\ AHP; \\ TOPSIS.
}

\begin{abstract}
Online product review websites have become excellent platforms for customers to share their opinions about a variety of products and services in the form of online reviews. Despite being an invaluable source of information for both consumers and firms, the quality of online reviews varies greatly. To tackle the problem of low quality reviews, in this paper, we address reviewer credibility problem and propose a novel framework for ranking reviewers in terms of credibility based on Interval Type-2 Fuzzy Analytical Hierarchy Process (IT2 FAHP) and technique for order performance by similarity to ideal solution (TOPSIS). The novel IT2 FAHP was used to determine weights of features representing reviewers, where the interval type-2 trapezoidal fuzzy numbers were used predominantly and TOPSIS method was used to obtain the final ranking of reviewers. To illustrate an application of the proposed framework, we conducted an experimental study using real data crawled from Epinions. This proposed framework provides a more effective and systematic approach, especially for firms, to find highly credible reviewers and select their reviews and opinions for opinion mining.
\end{abstract}

(C) 2016 Sharif University of Technology. All rights reserved.

\section{Introduction}

With the proliferation of Web 2.0 [1] innovations, consumers are able to share their knowledge and experience about a variety of products and services through exchanging opinions in opinion sharing communities (e.g., online product review websites). For instance, at product review websites, such as Epinions.com, Yelp.com, and Ciao.com, users (reviewers) can share their opinions on, preferences for, and experience with products. In fact, such websites have become excellent platforms on which consumers conduct product related Word Of Mouth (WOM) conversations [2]. Customer reviews as a form of User-Generated Content (UGC) can be considered as a valuable source of information for consumers in case of decision making about pur-

\footnotetext{
*. Corresponding author. Tel.: +982188678580;

Fax: +982188674858

E-mail address: mjtarokh@kntu.ac.ir (M.J. Tarokh)
}

chasing products. Several studies pointed out that online reviews have a great impact on consumers' decision-making [3-5]. Additionally, for firms and business enterprises, customer review is of high value. Firms can use text-mining techniques [6] to extract opinions of users about their products and services. So far, many studies have addressed the problem of opinion mining and sentiment analysis (e.g., [7-11]).

From a firm perspective, online customer reviews can be considered as a useful source for gaining knowledge about the needs and preferences of customers, strengths or weaknesses of products, and thereby devising good strategies to meet customer requirements. However, there are two main problems regarding online reviews: (1) The abundance of online reviews: Reviews are constantly increasing in number. For some products, the number of reviews is high, so it is difficult for consumers to read all the reviews contributed by other users to obtain useful information, and thus making a decision [12]; and (2) Variability in 
quality of online reviews: Online reviews vary greatly in terms of quality and credibility [13]. Actually, reviews are written by different people with different levels of knowledge and expertise. Including low quality reviews in a mining task will lead to low quality results; hence, low quality reviews should be identified and excluded in order to achieve valid, meaningful, and valuable results. "Peer reviewing" is the common mechanism for ranking reviews in online opinion sharing communities that allows members to evaluate and give helpful votes to the reviews of other members in order to indicate their informativeness. Unfortunately, this approach is not a completely useful mechanism to rank reviews [2]. For example, Liu et al. [14] discovered that users' votes at Amazon have three kinds of biases as follows: (a) imbalance vote bias; (b) winner circle bias; and (c) early bird bias. Therefore, there is a need for an effective approach to rank reviews.

To tackle the problem of review quality, we address user (reviewer) credibility since credibility assessment of source (e.g., reviewer) and message (e.g., review) are fundamentally and positively interlinked [15]. Motivated by the importance of identifying the most credible reviewers, in this study, we formulate reviewer ranking as a Multi-Criteria Decision Making (MCDM) problem and propose a novel framework for ranking reviewers in terms of credibility by combining our new interval type-2 fuzzy analytical hierarchy process and TOPSIS [16,17]. In this study, we firstly develop a novel Fuzzy Analytical Hierarchy Process (FAHP) [18,19] method by adopting the concept of Interval Type-2 Fuzzy Sets (IT2 FS) [20-26], and employ it in the presented framework to calculate the weights of utilized features for representing reviewers. Type-2 fuzzy sets can handle high-level uncertainties and imprecision in a better way [27].

With the introduction of Type-2 Fuzzy Sets (T2 FS) and the concept of Interval Type-2 Fuzzy Sets (IT2 FS), decisions should receive more comprehensive evaluation due to the flexibility of spaces representing uncertainties than they do with Type-1 Fuzzy Sets (T1 FS). T2 FS are described by a fuzzy membership function, i.e. the membership degree of each element of this set is a fuzzy set in [0,1], distinct from a T1 FS where the membership degree is a crisp number in $[0,1][20,21]$. Dereli et al. [28] provided a useful literature review of the industrial applications of type2 fuzzy sets in the three main areas, namely, manufacturing, service, and Information and Communication Technology (ICT), highlighting the basic reasons of the need for type-2 fuzzy sets for the existing studies. According to their research, there are several different domains to which type-2 FSs can be applied in order to provide a better solution. Currently, interval type2 fuzzy sets have been successfully applied to the design of intrusion detection system [29], technology evaluation [30,31], group decision making [23,24,32], evaluation and reduction of the bullwhip effect in supply chain [33], control systems [21,34-36], and pattern recognition $[37,38]$.

AHP is one of the most popular and widely used Multiple-Criteria Decision Making (MCDM) approaches introduced by Saaty $[18,39,40]$, which has its roots in determining the relative weights among the criteria and the total values of each alternative based on these weights. Since in the conventional AHP, human judgments are expressed in the form of crisp values, this method is unable to adequately handle uncertain and imprecise judgments of decision makers [41]. Therefore, various FAHP methods are proposed to deal with the uncertainty and impreciseness of decision makers' judgments [42]. Chang's FAHP [43] is a widely used method $[44,45]$. It uses fuzzy numbers from T1 FS. In this study, we aim to extend the Chang's method by adopting the concept of IT2 FS. Our developed fuzzy analytic hierarchy process with trapezoidal interval type-2 fuzzy numbers exploits the possibility degree developed by $\mathrm{Hu}$ et al. [46]. We apply our proposed method for determining the subjective weights of the utilized features representing reviewers. The proposed method can be applied to many practical applications of MCDM. As the proposed method is based on IT2 FS, the preference scale allows a more comprehensive judgment and can handle the uncertainty involved especially during the process of information gathering from decision makers.

The presented framework for ranking reviewers consists mainly of five stages: identification of source credibility dimensions, data collection and preprocessing, construction of features representing reviewers, determination of the weights of features, and ranking reviewers in terms of credibility. In the first stage, the two principal dimensions of source credibility, including expertise and trustworthiness, are identified through a comprehensive literature review. In the second stage, according to the two dimensions of source credibility, data about reviewers are collected from the web. Specifically, three kinds of data are collected, including: (a) reviewers' profile; (b) information about rating on users' reviews and reviews' metadata; and (c) trust network data. In the third stage, considering the collected data, the qualitative source credibility dimensions are mapped into some measurable quantitative features. In the fourth stage, as features may have different importance weights, the weights of the features are calculated using the new interval type-2 FAHP. In the final stage, reviewers are ranked using the TOPSIS method.

The main contributions of this paper are threefold. First, we identify the key dimensions of the source credibility through reviewing the relevant literature, then map these qualitative dimensions into 
some measurable features derived from three kinds of data, including reviewers' profile, information about rating on user reviews and reviews' metadata, and trust network data. Second, we develop a new FAHP method with trapezoidal interval type-2 fuzzy numbers, which is based on the FAHP method proposed by Chang [43] and the possibility degree presented by $\mathrm{Hu}$ et al. [46]. The proposed type- 2 fuzzy AHP is used to determine the weights of the utilized features. Furthermore, we employ the TOPSIS method to rank reviewers. Finally, to illustrate an application of the proposed approach, we conduct an experimental study using real data crawled from Epinions.

The rest of the paper is organized as follows. Section 2 reviews the source credibility of literature and describes concepts and methods, including interval type-2 fuzzy sets and TOPSIS. In Section 3, the proposed framework for ranking reviewers and portray the steps of the proposed interval type- 2 fuzzy AHP are described. Section 4 demonstrates a case study in which the presented framework is applied. Section 5, concludes the paper.

\section{Literature review}

\subsection{Source credibility}

Although credibility is a widely studied concept, there exists no single, clear definition of credibility. Rather, the overall view is that credibility is the believability of a source or message [47]. Definitions of credibility are somewhat discipline-based [47]. Whereas psychology and communication fields put more emphasis on source credibility, information science gives more importance to message or information credibility, that is, it views credibility in terms of information quality. Even so, these distinctions are not completely clean. For example, source credibility is often a criterion for evaluating information credibility [47].

Credibility dimensions are categorized into three kinds: Source credibility, message credibility, and medium credibility $[15,48]$. Credibility assessment of source and message are fundamentally and positively interlinked [15]. Information quality and source credibility are predictors of usefulness of information [48]. Credibility is a principal characteristic of information quality [48]. Considering this insight and in line with the research [15], in this paper, we focus on quantifying the credibility of reviewers in the product review websites to rank and identify the most credible reviews. In a product review website, the review, reviewer, and website can be considered as the message, source, and medium, respectively.

Source credibility was defined by Hovland, et al. (as cited in [15]) as expertise and trustworthiness. Despite the identification of several different dimensions for source credibility in the later studies, the initial two dimensions, expertise and trustworthiness, are still the focal dimensions [15]. Much of the research in the credibility context has focused on discovering the factors affecting the credibility of source without performing a quantitative evaluation [15]. However, there are few studies addressing the problem of measuring source credibility. In [15], a method to quantify the credibility of reviewers in TripAdvisor using the two novel indices, namely the impact index and the exposure-impact index, was developed. In [49], an algorithm called CredRank algorithm was presented to measure users' credibility based on their behavior in social media. In this study, we aim to measure reviewer credibility based on the two principal source credibility dimensions, including trustworthiness and expertise.

\subsection{Interval type-2 fuzzy sets}

Zadeh [50] developed the concept of a type-2 fuzzy set as an extension of the concept of a type- 1 fuzzy set. Type-2 fuzzy sets are used for modeling uncertainty and imprecision in a better way [51]. Distinct from a type- 1 fuzzy set where the membership degree is a crisp value in $[0,1]$, a type- 2 fuzzy set is described by a fuzzy membership function, i.e. the membership degree of each element of this set is a fuzzy set in [0,1] [21]. Type-1 fuzzy sets can be considered as a first order approximation to the uncertainty, while type-2 fuzzy sets can be viewed as a second order approximation. An interval type-2 fuzzy set is a special case of a full type-2 fuzzy set. The researchers preferred, generally, using interval valued type-2 FSs because of their simplicity and reduced computational complexity compared to general type-2 FSs [52]. In the following, we provide some definitions about type2 fuzzy sets.

Definition 1 [20]: A type-2 fuzzy set, $\tilde{\tilde{A}}$, in the universe of discourse $X$ can be represented by a type- 2 fuzzy membership function, $\mu_{\tilde{\tilde{A}}}$, shown as follows:

$$
\begin{aligned}
\tilde{\tilde{A}}= & \left\{\left((x, u), \mu_{\tilde{\tilde{A}}}(x, u)\right) \mid \forall x \in X, \forall u \in J_{x} \subseteq[0,1],\right. \\
& \left.0 \leq \mu_{\tilde{\tilde{A}}}(x, u) \leq 1\right\},
\end{aligned}
$$

where $J_{x}$ denotes an interval in $[0,1]$.

Definition 2 [20]: The type-2 fuzzy set, $\tilde{\tilde{A}}$, can also be represented as follows:

$$
\tilde{\tilde{A}}=\int_{x \in X} \int_{u \in J_{x}} \mu_{\tilde{\tilde{A}}}(x, u) /(x, u),
$$

where $J_{x} \subseteq[0,1]$ and $\iint$ denote union over all admissible $x$ and $u$. 
Definition 3 [20]: For a type-2 fuzzy set, $\tilde{\tilde{A}}$, if all $\mu_{\tilde{\tilde{A}}}=1$, then $\tilde{\tilde{A}}$ is called an interval type- 2 fuzzy set. An interval type-2 fuzzy set can be considered as a special case of a type- 2 fuzzy set defined by the following relation:

$$
\tilde{\tilde{A}}=\int_{x \in X} \int_{u \in J_{x}} 1 /(x, u)
$$

where $J_{x} \subseteq[0,1]$.

Definition 4 [20]: Let $\tilde{\tilde{A}}$ be an interval type-2 fuzzy set. Uncertainty in the primary memberships of $\tilde{\tilde{A}}$ consists of a bounded region called the Footprint Of Uncertainty (FOU), which is the union of all primary memberships. FOU is characterized by Upper Membership Function (UMF) and Lower Membership Function (LMF). Both UMF and LMF are type-1 membership functions.

Definition 5 [23,53]: A trapezoidal interval type-2 fuzzy number $\tilde{A}$ is represented by:

$$
\begin{aligned}
\tilde{\tilde{A}}= & \left(\tilde{A}^{U}, \tilde{A}^{L}\right)=\left(\left(a_{1}^{U}, a_{2}^{U}, a_{3}^{U}, A_{4}^{U} ; H_{1}\left(\tilde{A}^{U}\right), H_{2}\left(\tilde{A}^{U}\right)\right),\right. \\
& \left.\left(a_{1}^{L}, a_{2}^{L}, a_{3}^{L}, a_{4}^{L} ; H_{1}\left(\tilde{A}^{L}\right), H_{2}\left(\tilde{A}^{L}\right)\right)\right),
\end{aligned}
$$

where both $\tilde{A}^{U}$ and $\tilde{A}^{L}$ are type-1 fuzzy sets; $a_{1}^{U}, a_{2}^{U}, a_{3}^{U} a_{4}^{U}, a_{1}^{L}, a_{2}^{L}, a_{3}^{L}$, and $a_{4}^{L}$ are the reference points of the trapezoidal interval type-2 fuzzy set $\tilde{A} ; H_{i}\left(\tilde{A}^{U}\right)$ represents the membership value of the element $a_{i+1}^{U}$ in the upper trapezoidal membership function $A^{U}, 1 \leq i \leq 2 ; H_{i}\left(\tilde{A}^{L}\right)$ represents the membership value of the element $a_{i+1}^{L}$ in the lower trapezoidal membership function $A^{L}, 1 \leq i \leq 2$.

Definition $6[23,53]$ : Suppose that $\tilde{A}_{1}$ and $\tilde{A}_{2}$ are two trapezoidal interval type-2 fuzzy numbers:

$$
\begin{aligned}
\tilde{\tilde{A}}_{1}=\left(\tilde{A}_{1}^{U}, \tilde{A}_{1}^{L}\right)= & \left(\left(a_{11}^{U}, a_{12}^{U}, a_{13}^{U}, a_{14}^{U} ; H_{1}\left(\tilde{A}_{1}^{U}\right),\right.\right. \\
& \left.H_{2}\left(\tilde{A}_{1}^{U}\right)\right),\left(\left(a_{11}^{L}, a_{12}^{L}, a_{13}^{L}, a_{14}^{L} ;\right.\right. \\
& \left.\left.H_{1}\left(\tilde{A}_{1}^{L}\right), H_{2}\left(\tilde{A}_{1}^{L}\right)\right)\right) \\
\tilde{\tilde{A}}_{2}=\left(\tilde{A}_{2}^{U}, \tilde{A}_{2}^{L}\right)= & \left(\left(a_{21}^{U}, a_{22}^{U}, a_{23}^{U}, a_{24}^{U} ; H_{1}\left(\tilde{A}_{2}^{U}\right),\right.\right. \\
& \left.H_{2}\left(\tilde{A}_{2}^{U}\right)\right),\left(\left(a_{21}^{L}, a_{22}^{L}, a_{23}^{L}, a_{24}^{L} ;\right.\right. \\
& \left.\left.H_{1}\left(\tilde{A}_{2}^{L}\right), H_{2}\left(\tilde{A}_{2}^{L}\right)\right)\right) .
\end{aligned}
$$

The basic algebraic operations of the IT2 FS sets $\tilde{\tilde{A}}_{1}$ and $\tilde{\tilde{A}}_{2}$ are given in Eqs. (5)-(7).

The additional operation between $\tilde{\tilde{A}}_{1}$ and $\tilde{\tilde{A}}_{2}$ is defined by Eq. (5) as shown in Box I.

The multiplication operation between $\tilde{\tilde{A}}_{1}$ and $\tilde{\tilde{A}}_{2}$ is defined by Eq. (6) as shown in Box II.

The subtraction operation between $\tilde{\tilde{A}}_{1}$ and $\tilde{\tilde{A}}_{2}$ is defined by Eq. (7) as shown in Box III. The arithmetic operation between the crisp value $k$ and $\tilde{\tilde{A}}_{1}$ is defined as follows:

$$
\begin{aligned}
k \tilde{\tilde{A}}_{1}= & \left(\left(k \times a_{11}^{U}, k \times a_{12}^{U}, k \times a_{13}^{U}, k \times a_{14}^{U} ; H_{1}\left(\tilde{A}_{1}^{U}\right)\right.\right. \\
& \left.\left.H_{2}\left(\tilde{A}_{1}^{U}\right)\right)\right),\left(k \times a_{11}^{L}, k \times a_{12}^{L}, k \times a_{13}^{L}, k \times a_{14}^{L}\right. \\
& \left.\left.H_{1}\left(\tilde{A}_{1}^{L}\right), H_{2}\left(\tilde{A}_{1}^{L}\right)\right)\right)
\end{aligned}
$$

where $k>0$.

$$
\tilde{\tilde{A}}_{1} \oplus \tilde{\tilde{A}}_{2}=\left(\begin{array}{c}
\left(a_{11}^{U}+a_{21}^{U}, a_{12}^{U}+a_{22}^{U}, a_{13}^{U}+a_{23}^{U}, a_{14}^{U}+a_{24}^{U} ; \min \left(H_{1}\left(\tilde{A}_{1}^{U}\right), H_{1}\left(\tilde{A}_{2}^{U}\right)\right), \min \left(H_{2}\left(\tilde{A}_{1}^{U}\right), H_{2}\left(\tilde{A}_{2}^{U}\right)\right)\right), \\
\left(a_{11}^{L}+a_{21}^{L}, a_{12}^{L}+a_{22}^{L}, a_{13}^{L}+a_{23}^{L}, a_{14}^{L}+a_{24}^{L} ; \min \left(H_{1}\left(\tilde{A}_{1}^{L}\right), H_{1}\left(\tilde{A}_{2}^{L}\right)\right), \min \left(H_{2}\left(\tilde{A}_{1}^{L}\right), H_{2}\left(\tilde{A}_{2}^{L}\right)\right)\right)
\end{array}\right)
$$

Box I

$$
\tilde{\tilde{A}}_{1} \otimes \tilde{\tilde{A}}_{2}=\left(\begin{array}{c}
\left(a_{11}^{U} \times a_{21}^{U}, a_{12}^{U} \times a_{22}^{U}, a_{13}^{U} \times a_{23}^{U}, a_{14}^{U} \times a_{24}^{U} ; \min \left(H_{1}\left(\tilde{A}_{1}^{U}\right), H_{1}\left(\tilde{A}_{2}^{U}\right)\right), \min \left(H_{2}\left(\tilde{A}_{1}^{U}\right), H_{2}\left(\tilde{A}_{2}^{U}\right)\right)\right), \\
\left(a_{11}^{L} \times a_{21}^{L}, a_{12}^{L} \times a_{22}^{L}, a_{13}^{L} \times a_{23}^{L}, a_{14}^{L} \times a_{24}^{L} ; \min \left(H_{1}\left(\tilde{A}_{1}^{L}\right), H_{1}\left(\tilde{A}_{2}^{L}\right)\right), \min \left(H_{2}\left(\tilde{A}_{1}^{L}\right), H_{2}\left(\tilde{A}_{2}^{L}\right)\right)\right)
\end{array}\right)
$$




$$
\tilde{\tilde{A}}_{1}(-) \tilde{\tilde{A}}_{2}=\left(\begin{array}{c}
\left(a_{11}^{U}-a_{21}^{U}, a_{12}^{U}-a_{22}^{U}, a_{13}^{U}-a_{23}^{U}, a_{14}^{U}-a_{24}^{U} ; \min \left(H_{1}\left(\tilde{A}_{1}^{U}\right), H_{1}\left(\tilde{A}_{2}^{U}\right)\right), \min \left(H_{2}\left(\tilde{A}_{1}^{U}\right), H_{2}\left(\tilde{A}_{2}^{U}\right)\right)\right), \\
\left(a_{11}^{L}-a_{21}^{L}, a_{12}^{L}-a_{22}^{L}, a_{13}^{L}-a_{23}^{L}, a_{14}^{L}-a_{24}^{L} ; \min \left(H_{1}\left(\tilde{A}_{1}^{L}\right), H_{1}\left(\tilde{A}_{2}^{L}\right)\right), \min \left(H_{2}\left(\tilde{A}_{1}^{L}\right), H_{2}\left(\tilde{A}_{2}^{L}\right)\right)\right)
\end{array}\right)
$$

\section{Box III}

$$
\frac{\tilde{\tilde{A}}_{1}}{\tilde{\tilde{A}}_{2}}=\left(\begin{array}{c}
\left(a_{11}^{U} / a_{21}^{U}, a_{12}^{U} / a_{22}^{U}, a_{13}^{U} / a_{23}^{U}, a_{14}^{U} / a_{24}^{U} ; \min \left(H_{1}\left(\tilde{A}_{1}^{U}\right), H_{1}\left(\tilde{A}_{2}^{U}\right)\right), \min \left(H_{2}\left(\tilde{A}_{1}^{U}\right), H_{2}\left(\tilde{A}_{2}^{U}\right)\right)\right), \\
\left(a_{11}^{L} / a_{21}^{L}, a_{12}^{L} / a_{22}^{L}, a_{13}^{L} / a_{23}^{L}, a_{14}^{L} / a_{24}^{L} ; \min \left(H_{1}\left(\tilde{A}_{1}^{L}\right), H_{1}\left(\tilde{A}_{2}^{L}\right)\right), \min \left(H_{2}\left(\tilde{A}_{1}^{L}\right), H_{2}\left(\tilde{A}_{2}^{L}\right)\right)\right)
\end{array}\right)
$$

Box IV

The division, inverse, and root operations between $\tilde{\tilde{A}}_{1}$ and $\tilde{\tilde{A}}_{2}$ are defined in Eq. (9) as shown in Box IV and Eqs. (10) and (11) as follows [54,55]:

$$
\begin{gathered}
\frac{1}{\tilde{\tilde{A}}_{1}}=\left(\left(\frac{1}{a_{14}^{U}}, \frac{1}{a_{13}^{U}}, \frac{1}{a_{12}^{U}}, \frac{1}{a_{11}^{U}} ; H_{1}\left(\tilde{A}_{1}^{U}\right), H_{2}\left(\tilde{A}_{1}^{U}\right)\right)\right), \\
\\
\left.\left(\frac{1}{a_{14}^{L}}, \frac{1}{a_{13}^{L}}, \frac{1}{a_{12}^{L}}, \frac{1}{a_{11}^{L}} ; H_{1}\left(\tilde{A}_{1}^{L}\right), H_{2}\left(\tilde{A}_{1}^{L}\right)\right)\right) .
\end{gathered}
$$

$n$th root of a trapezoidal interval type- 2 fuzzy set is defined as follows:

$$
\begin{aligned}
\sqrt[n]{\tilde{\tilde{A}}_{1}}= & \left(\left(\sqrt[n]{a_{11}^{U}}, \sqrt[n]{a_{12}^{U}}, \sqrt[n]{a_{13}^{U}}, \sqrt[n]{a_{14}^{U}} ; H_{1}\left(\tilde{A}_{1}^{U}\right)\right.\right. \\
& \left.H_{2}\left(\tilde{A}_{1}^{U}\right)\right),\left(\sqrt[n]{a_{11}^{L}}, \sqrt[n]{a_{12}^{L}}, \sqrt[n]{a_{13}^{L}}, \sqrt[n]{a_{14}^{L}} ;\right. \\
& \left.\left.H_{1}\left(\tilde{A}_{1}^{L}\right), H_{2}\left(\tilde{A}_{1}^{L}\right)\right)\right)
\end{aligned}
$$

\subsection{TOPSIS}

The Technique for Order Preferences by Similarity to an Ideal Solution (TOPSIS) method was proposed by Hwang and Yoon [16] to determine the best alternative based on the concepts of the compromise solution. The compromise solution can be regarded as the selection of the solution with the nearest distance from the ideal solution and the farthest distance from the negative ideal solution [17].

Suppose a set of alternatives, $A=\left\{A_{i} \mid i=1, \ldots, n\right\}$ and a set of criteria, $C=\left\{C_{j} \mid j=1, \ldots, m\right\}$, where $X=\left\{x_{i j} \mid i=1, \ldots, n ; j=1, \ldots, n\right\}$ denotes the set of performance ratings and $W=\left\{w_{j} \mid j=1, \ldots, m\right\}$ is the set of weights corresponding to the set of criteria. The procedures of TOPSIS can be described as follows:

- Step 1: Obtain the normalized decision matrix using:

$$
r_{i j}=\frac{x_{i j}}{\sum_{i=1}^{n} x_{i j}^{2}}, \quad i=1, \ldots, n ; \quad j=1, \ldots, m
$$

- Step 2: Calculate the weighted normalized decision matrix:

$$
v_{i j}=w_{j} r_{i j}, \quad i=1, \ldots, n ; \quad j=1, \ldots, m .
$$

- Step 3: Identify the ideal and the anti-ideal points, $v^{+}$and $v^{-}$, respectively as below:

$$
v^{+}=\left(v_{1}^{+}, \ldots, v_{n}^{+}\right) \text {and } v^{-}=\left(v_{1}^{-}, \ldots, v_{n}^{-}\right),
$$

where:

$$
v_{j}^{+}= \begin{cases}\max _{i} v_{i j}, & j \in J \\ \min _{i} v_{i j}, & j \in J^{\prime}\end{cases}
$$

and:

$$
v_{j}^{-}=\left\{\begin{array}{l}
\min _{i} v_{i j}, j \in J \\
\max _{i} v_{i j}, j \in J^{\prime}
\end{array}\right.
$$

$J$ and $J^{\prime}$ are the sets of "benefit" criteria and "cost" criteria, respectively.

- Step 4: Calculate the distance from the ideal and the anti-ideal points using Euclidean distance:

$$
D_{i}^{+}=\left(\sum_{j=1}^{m}\left(v_{i j}-v_{j}^{+}\right)^{2}\right)^{1 / 2}, \quad i=1, \ldots n
$$

(distance of the $i$-th alternative from the ideal)

$$
D_{i}^{-}=\left(\sum_{j=1}^{m}\left(v_{i j}-v_{j}^{-}\right)^{2}\right)^{1 / 2}, \quad i=1, \ldots n .
$$

(distance of the $i$-th alternative from the anti-ideal)

- Step 5: Calculate the relative closeness of each alternative to the ideal point. 


$$
C_{i}=\frac{D_{i}^{-}}{D_{i}^{-}+D_{i}^{+}}, \quad i=1, \ldots, n
$$

where $0 \leq C_{i} \leq 1$. The larger the value $C_{i}$ is, the better the performance of an alternative will be.

- Step 6: Rank the alternatives. Alternatives are ranked according to the descending order of the value of $C_{i}$ [17].

TOPSIS has been applied successfully to various domains, such as supply chain management (e.g., [56]), business and marketing (e.g., [57]), manufacturing (e.g., [58]), and human resources management (e.g., [59]).

\section{Proposed approach}

\subsection{Overview}

The framework of our proposed approach is illustrated in Figure 1. As depicted in Figure 1, the process consists of five important parts: discovering source credibility dimensions, crawling data, constructing the required features, weighting features using interval type2 fuzzy AHP (IT2 FAHP) method, and ranking reviewers with TOPSIS. In the following, we explain in detail the steps of the process.

\subsection{Analyzing the source credibility problem}

In the first stage, we analyze the problem of source credibility and investigate its main dimensions through a comprehensive literature review.

\subsection{Crawling data from the web}

The second critical stage is the crawling stage, in which the required data are collected from the web according to the qualitative factors discovered in the previous stage.

\subsection{Constructing the required features}

In this stage, the required quantitative features relevant to the qualitative factors are extracted and derived from the crawled data. Therefore, each reviewer is represented by a feature vector.

\subsection{Weighting features using Fuzzy AHP with interval type-2 fuzzy numbers}

Since we formulate the reviewer rankings as an MCDM problem in this paper, we consider the derived features, in the previous phase as the criteria and the reviewers as the alternatives. For calculating the weights of the criteria, we firstly present a new interval type-2 fuzzy AHP method. In the following, we describe our novel Interval Type-2 Fuzzy AHP (IT2 FAHP).

\subsubsection{IT2 FAHP}

Our developed fuzzy analytic hierarchy process with trapezoidal interval type-2 fuzzy numbers is based on the fuzzy AHP method proposed by Chang [43] and the possibility degree presented by $\mathrm{Hu}$ et al. [46]. $\mathrm{Hu}$ et al. [46] had compared their proposed method with other previously developed methods, including the possibility degree method proposed by Chen and Lee [23] and ranking value method [22]. According to their investigation, the main advantage of the method developed by $\mathrm{Hu}$ et al. [46] compared with Chen's method [23] is that the possibility degree is computed only once rather than twice in Chen's method, as it

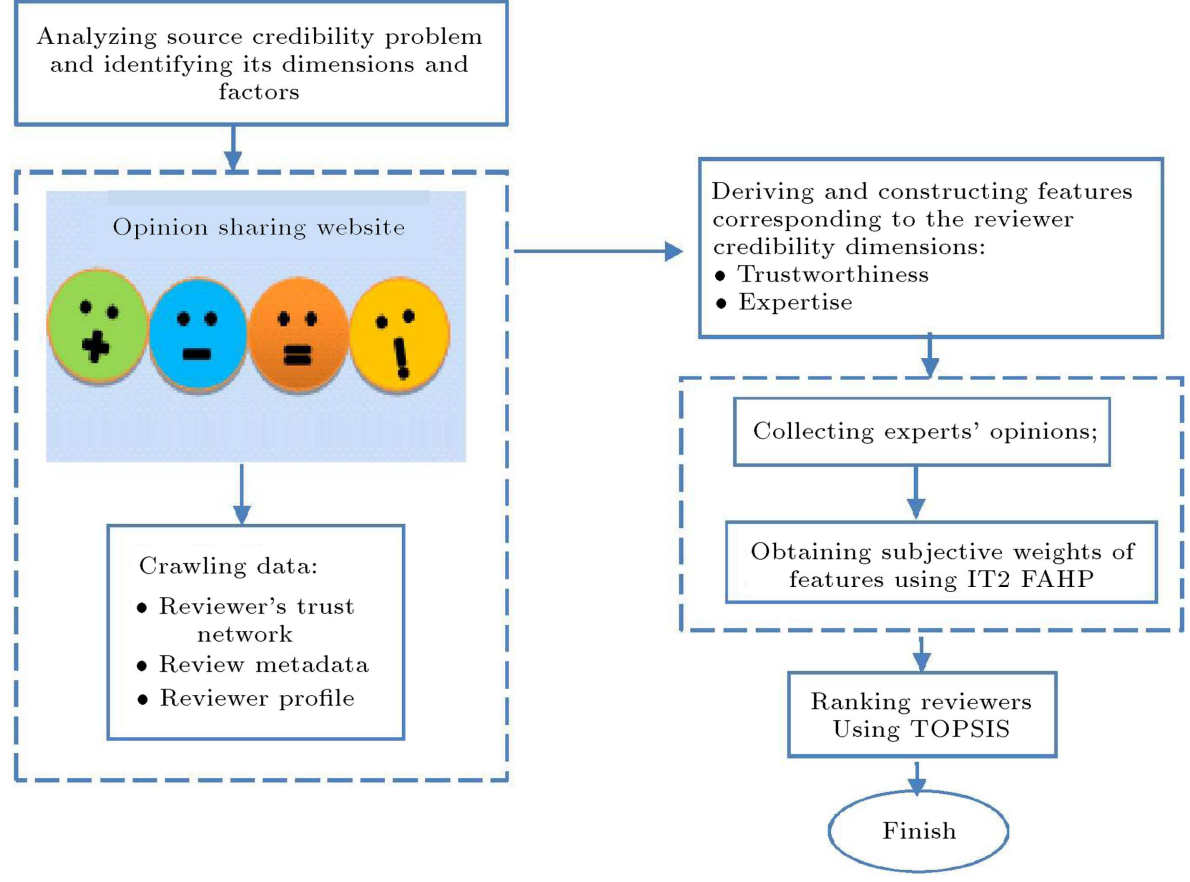

Figure 1. The methodology of research. 
considers the values of Upper and Lower Membership Functions (UMF and LMF) at the same time. So, the computation time is reduced.

In addition, the advantages of Hu's method [46], when compared with ranking value method [22], are:

1. Its computation is simpler because the ranking value method uses some complex operations, such as square root;

2. According to the results of Hu's paper, ranking based on Hu's method is easier than Chen's method [22], because the calculated ranking values of all alternatives are larger than the one of Chen's method. That is, the computed ranking values of all alternatives are close based on Chen's method.

Therefore, in this paper, we utilize the possibility degree presented by $\mathrm{Hu}$ et al. [46].

The steps of the new IT2 FAHP for determining the weights of $n$ features are as follows:

- Step 1: Construct the fuzzy comparison matrix of $n$ features.

A comparison matrix $\tilde{A}$ is constructed as:

$$
\tilde{\tilde{A}}=\left[\begin{array}{cccc}
1 & \tilde{\tilde{a}}_{12} & \ldots & \tilde{\tilde{a}}_{1 n} \\
1 / \tilde{\tilde{a}}_{21} & 1 & \ldots & \tilde{\tilde{a}}_{2 n} \\
\vdots & \vdots & \ddots & \vdots \\
1 / \tilde{\tilde{a}}_{n 1} & 1 / \tilde{\tilde{a}}_{n 2} & \ldots & 1
\end{array}\right]
$$

where:

$$
\begin{aligned}
\tilde{\tilde{a}}= & \left(\left(\tilde{\tilde{a}}_{11}^{U}, \tilde{\tilde{a}}_{12}^{U}, \tilde{\tilde{a}}_{13}^{U}, \tilde{\tilde{a}}_{14}^{U} ; H_{1}\left(\tilde{\tilde{a}}^{U}\right), H_{2}\left(\tilde{\tilde{a}}^{U}\right)\right),\left(\tilde{\tilde{a}}_{21}^{L},\right.\right. \\
& \left.\left.\tilde{\tilde{a}}_{22}^{L}, \tilde{\tilde{a}}_{23}^{L}, \tilde{\tilde{a}}_{24}^{L} ; H_{1}\left(\tilde{\tilde{a}}^{L}\right), H_{2}\left(\tilde{\tilde{a}}^{L}\right)\right)\right)
\end{aligned}
$$

and:

$$
\begin{aligned}
\frac{1}{\tilde{\tilde{a}}}= & \left(\left(\frac{1}{\tilde{\tilde{a}}_{14}^{U}}, \frac{1}{\tilde{\tilde{a}}_{13}^{U}}, \frac{1}{\tilde{\tilde{a}}_{12}^{U}}, \frac{1}{\tilde{\tilde{a}}_{11}^{U}} ; H_{1}\left(\tilde{\tilde{a}}^{U}\right), H_{2}\left(\tilde{\tilde{a}}^{U}\right)\right),\right. \\
& \left.\left(\frac{1}{\tilde{\tilde{a}}_{14}^{L}}, \frac{1}{\tilde{\tilde{a}}_{13}^{U}}, \frac{1}{\tilde{\tilde{a}}_{12}^{L}}, \frac{1}{\tilde{\tilde{a}}_{11}^{L}} ; H_{1}\left(\tilde{\tilde{a}}^{L}\right), H_{2}\left(\tilde{\tilde{a}}^{L}\right)\right)\right) .
\end{aligned}
$$

- Step 2: Check the consistency of the pairwise comparison matrices.

In this step, the consistency of each fuzzy pairwise comparison matrix is evaluated. In order to check the consistency of the fuzzy pairwise comparison matrices, pairwise comparison values are defuzzified using the proposed defuzzification method (DTITFN). Suppose $\tilde{\tilde{A}}=\left[\tilde{\tilde{a}}_{i j}\right]$ is a fuzzy positive reciprocal matrix and $A=\left[a_{i j}\right]$ is a positive reciprocal matrix. According to the result of Buckley [60], if the result of the comparisons of $A=\left[a_{i j}\right]$ is consistent, then it can imply that the result of the comparisons of $\tilde{\tilde{A}}=\left[\tilde{\tilde{a}}_{i j}\right]$ is also consistent.

- Step 2.1: Defuzzify the pairwise comparison values.

Defuzzification of each matrix is accomplished using the presented DTITFN method. Here, DTITFN (Defuzzification of Trapezoidal Interval Type-2 Fuzzy Numbers) is described as follows.

DTITFN is based on the graded mean integration representation of generalized fuzzy number introduced by Chen and Hsieh [61]. Assume that:

$$
\begin{aligned}
\tilde{\tilde{A}}= & \left(\left(a_{11}, a_{12}, a_{13}, a_{14} ; H_{1}\left(\tilde{A}^{U}\right), H_{2}\left(\tilde{A}^{U}\right)\right)\right. \\
& \left.\left(a_{21}, a_{22}, a_{23}, a_{24} ; H_{1}\left(\tilde{A}^{L}\right), H_{2}\left(\tilde{A}^{L}\right)\right)\right)
\end{aligned}
$$

is a trapezoidal interval type-2 fuzzy number; the steps of obtaining the Defuzzified Trapezoidal Interval Type-2 Fuzzy Number (DTITFN) are as follows:

(i) Compute $W_{1}$ by averaging the membership values of the two reference points; $a_{12}$ and $a_{13}$ of the upper membership function, $\tilde{A}^{U}$, which are $H_{1}\left(\tilde{A}^{U}\right)$ and $H_{2}\left(\tilde{A}^{U}\right)$, respectively:

$$
W_{1}=\frac{H_{1}\left(\tilde{A}^{U}\right)+H_{2}\left(\tilde{A}^{U}\right)}{2} .
$$

(ii) Compute $W_{2}$ by averaging the membership values of the two reference points; $a_{22}$ and $a_{23}$ of the lower membership function, $\tilde{\tilde{A}}^{L}$, which are $H_{1}\left(\tilde{A}^{L}\right)$ and $H_{2}\left(\tilde{A}^{L}\right)$, respectively.

$$
W_{2}=\frac{H_{1}\left(\tilde{A}^{L}\right)+H_{2}\left(\tilde{A}^{L}\right)}{2} .
$$

(iii) Derive $\tilde{A}_{1}=\left(a_{11}, a_{12}, a_{13}, a_{14} ; W_{1}\right)$ and $\tilde{A}_{2}$ $=\left(a_{21}, a_{22}, a_{23}, a_{24} ; W_{2}\right)$ from $\tilde{\tilde{A}}$.

(iv) Compute the grade mean integration representation of $\tilde{A}_{1}$ and $\tilde{A}_{2}$.

Let $\tilde{M}=(a, b, c, d ; W)$ be a trapezoidal fuzzy number, then the graded mean integration representation of $\tilde{M}$ is:

$$
\begin{aligned}
P(\tilde{M})= & \int_{0}^{W} y\left(\frac{L^{-1}(y)+R^{-1}(y)}{2}\right) d y \\
& / \int_{0}^{W} y d y
\end{aligned}
$$


where:

$$
\begin{aligned}
L(x)= & \left(\frac{x-a}{b-a}\right), \\
L^{-1}(y)= & a+(b-1) y \\
P(\tilde{M})= & \frac{1}{2} \int_{0}^{W} y[((a+(b-a) y)+(d) \\
& -(d-c) y))] d y / \int_{0}^{W} y d y \\
& =\frac{1}{2} \int_{0}^{W} y[(a+d)+(b-a \\
& -d+c) y] d y / \int_{0}^{W} y d y \\
& =\frac{1}{2} \int_{0}^{W}[(a+d) y+(b-a \\
& =\frac{1}{2}=\frac{(a+d)}{2}+\frac{(b-a-d+c) W}{3} \\
& \left.-d+c) y^{2}\right] d y / \int_{0}^{W} y d y \\
& \\
& \\
& \\
& \\
& \\
&
\end{aligned}
$$

(v) Calculate the defuzzified value of $\tilde{\tilde{A}}$ (DTITFN) as follows:

$$
\operatorname{DTITFN}=\frac{W_{1}\left(P\left(\tilde{A}_{1}\right)\right)+W_{2}\left(P\left(\tilde{A}_{2}\right)\right)}{W_{1}+W_{2}},
$$

where $W_{1}$ and $W_{2}$ are determined by Steps 1 and 2, respectively; $P\left(\tilde{A}_{1}\right)$ and $P\left(\tilde{A}_{2}\right)$ which are the graded mean integration representation of $\tilde{A}_{1}$ and $\tilde{A}_{2}$ are calculated using Eqs. (27) and (28):

$$
\begin{aligned}
P\left(\tilde{A}_{1}\right)= & \frac{\left(a_{11}+a_{14}\right)}{2} \\
& +\frac{W_{1}\left(a_{12}-a_{11}-a_{14}+a_{13}\right)}{3}, \\
P\left(\tilde{A}_{2}\right)= & \frac{\left(a_{21}+a_{24}\right)}{2} \\
& +\frac{W_{2}\left(a_{22}-a_{21}-a_{24}+a_{23}\right)}{3} .
\end{aligned}
$$

- Step 2.2: Check consistency of the defuzzified matrix.

Exploiting the proposed method DTITFN, the defuzzified pairwise comparison matrix is obtained, which thereafter is used for the examination of the consistency. The consistency of the defuzzified pairwise comparison matrix can be examined by the Consistency Ratio (CR) [18], which is defined as:

$$
\begin{aligned}
& \mathrm{CR}=\frac{\mathrm{CI}}{\mathrm{RI}}, \\
& \mathrm{CI}=\frac{\lambda_{\max }-n}{n-1},
\end{aligned}
$$

where CI is the Consistency Index, RI is the Random Index which is the average consistency index of a randomly generated reciprocal matrix, $n$ is the size of matrix, $\lambda_{\max }$ is the largest eigenvalue of the comparison matrix. Depending on the size of the matrix, $n$, an appropriate value of $\mathrm{RI}$ is selected to calculate CR. RI values are seen in Table 1. Saaty [18] suggests that CR should be less than 0.1 in order for comparison matrix to be consistent and acceptable.

- Step 3: Aggregate the opinions of experts.

In this step, the opinions of experts are aggregated using the geometric mean according to Eq. (31):

$$
\tilde{\tilde{a}}_{i j}=\left(\tilde{\tilde{a}}_{i j}^{1} \otimes \tilde{\tilde{a}}_{i j}^{2} \otimes \ldots \otimes \tilde{\tilde{a}}_{i j}^{t}\right)^{\frac{1}{t}},
$$

where $t$ is the number of experts.

- Step 4: Apply the fuzzy extent analysis [43].

First, each row of the fuzzy comparison matrix is summed using Eq. (32):

$$
\tilde{\tilde{r}}_{i}=\left[\tilde{\tilde{a}}_{i 1} \oplus \ldots \oplus \tilde{\tilde{a}}_{\text {in }}\right] \text {. }
$$

Then, the row sums are normalized using Eq. (33):

$$
\begin{aligned}
& \tilde{\tilde{S}}_{i}=\tilde{\tilde{r}}_{i} \otimes\left[\tilde{\tilde{r}}_{1} \oplus \ldots \oplus \tilde{\tilde{r}}_{i} \oplus \ldots \oplus \ldots \tilde{\tilde{r}}_{n}\right]^{-1}, \\
& i=1,2, \ldots, n .
\end{aligned}
$$

- Step 5: Compute the possibility degree matrix.

Suppose that $\tilde{\tilde{S}}_{i}$ and $\tilde{\tilde{S}}_{j}$ are two trapezoidal interval type-2 fuzzy numbers:

$$
\begin{gathered}
\tilde{\tilde{S}}_{i}=\left(\tilde{S}_{i}^{U}, \tilde{S}_{i}^{L}\right)=\left(s_{i 1}^{U}, s_{i 2}^{U}, s_{i 3}^{U}, s_{i 4}^{U} ; H_{1}\left(\tilde{S}_{i}^{U}\right), H_{2}\left(\tilde{S}_{i}^{U}\right)\right), \\
\left(s_{i 1}^{L}, s_{i 2}^{L}, s_{i 3}^{L}, s_{i 4}^{L} ; H_{1}\left(\tilde{S}_{i}^{L}\right), H_{2}\left(\tilde{S}_{i}^{L}\right)\right),
\end{gathered}
$$

Table 1. The random consistency index (RI) [18].

\begin{tabular}{cccccccccc}
\hline Size & $\mathbf{1}$ & $\mathbf{2}$ & $\mathbf{3}$ & $\mathbf{4}$ & $\mathbf{5}$ & $\mathbf{6}$ & $\mathbf{7}$ & $\mathbf{8}$ & $\mathbf{9}$ \\
\hline RI & 0.00 & 0.00 & 0.52 & 0.89 & 1.11 & 1.25 & 1.35 & 1.40 & 1.45
\end{tabular}




$$
\begin{gathered}
\tilde{\tilde{S}}_{j}=\left(\tilde{S}_{j}^{U}, \tilde{S}_{j}^{L}\right)=\left(s_{j 1}^{U}, s_{j 2}^{U}, s_{j 3}^{U}, s_{j 4}^{U} ; H_{1}\left(\tilde{S}_{j}^{U}\right), H_{2}\left(\tilde{S}_{j}^{U}\right)\right) \\
\left(s_{j 1}^{L}, s_{j 2}^{L}, s_{j 3}^{L}, s_{j 4}^{L} ; H_{1}\left(\tilde{S}_{j}^{L}\right), H_{2}\left(\tilde{S}_{j}^{L}\right)\right) .
\end{gathered}
$$

Then, the possibility degree of $\tilde{\tilde{S}}_{i}$ over $\tilde{\tilde{S}}_{j}$ is defined by Eqs. (34) and (35) as shown in Box V [46], where:

$$
\begin{aligned}
& \operatorname{len}\left(v_{1}\right)=s_{i 4}^{L}+s_{i 3}^{L}-s_{i 1}^{L}-s_{i 2}^{L}, \\
& \operatorname{len}\left(v_{2}\right)=s_{i 4}^{U}+s_{i 3}^{U}-s_{i 1}^{U}-s_{i 2}^{U}, \\
& \operatorname{len}\left(v_{3}\right)=s_{j 4}^{L}+s_{j 3}^{L}-s_{j 1}^{L}-s_{j 2}^{L}, \\
& \operatorname{len}\left(v_{4}\right)=s_{j 4}^{U}+s_{j 3}^{U}-s_{j 1}^{U}-s-j 2^{U} .
\end{aligned}
$$

To compare $n$ trapezoidal interval type-2 fuzzy numbers, $\left\{\tilde{\tilde{S}}_{1}, \ldots, \tilde{\tilde{S}}_{i}, \ldots, \tilde{\tilde{S}}_{n}\right\}$, establish the possibility degree matrix as follows:

$$
\begin{gathered}
P= \\
{\left[\begin{array}{cccc}
p\left(\tilde{\tilde{S}}_{1} \geq \tilde{\tilde{S}}_{1}\right) & p\left(\tilde{\tilde{S}}_{1} \geq \tilde{\tilde{S}}_{2}\right) & \ldots & p\left(\tilde{\tilde{S}}_{1} \geq \tilde{\tilde{S}}_{n}\right) \\
p\left(\tilde{\tilde{S}}_{2} \geq \tilde{\tilde{S}}_{1}\right) & p\left(\tilde{\tilde{S}}_{2} \geq \tilde{\tilde{S}}_{2}\right) & \ldots & p\left(\tilde{\tilde{S}}_{2} \geq \tilde{\tilde{S}}_{n}\right) \\
\vdots & \vdots & \ddots & \vdots \\
p\left(\tilde{\tilde{S}}_{n} \geq \tilde{\tilde{S}}_{1}\right) & p\left(\tilde{\tilde{S}}_{n} \geq \tilde{\tilde{S}}_{2}\right) & \ldots & p\left(\tilde{\tilde{S}}_{n} \geq \tilde{\tilde{S}}_{n}\right)
\end{array}\right]}
\end{gathered}
$$

- Step 6: Calculate the crisp weights of the features.

After calculating the possibility degree matrix, obtain ranking values of $\left\{\tilde{S}_{1}, \ldots, \tilde{S}_{i}, \ldots, \tilde{S}_{n}\right\}$ based on the following equation [62]:

$$
\begin{aligned}
& \operatorname{Rank}_{i}=\frac{1}{n(n-1)}\left(\sum_{j=1}^{n} p_{i j}+\frac{1}{2}-1\right), \\
& i=1,2, \ldots, n .
\end{aligned}
$$

Obtain weights of the features by normalizing the ranking values as follows:

$$
w_{i}^{s}=\frac{\operatorname{rank}_{i}}{\sum_{i=1}^{n} \operatorname{rank}_{i}} .
$$

\subsection{Ranking the reviewers using TOPSIS}

In this stage, based on the derived features and the obtained weights via IT2FAHP, TOPSIS is applied to rank the reviewers.

\section{Empirical case study}

In this section, we conduct an empirical case study using data crawled from Epinions.com to illustrate the effectiveness of the proposed framework.

\subsection{Analyzing the source credibility problem of online reviews}

In the first stage, we analyzed the problem of source credibility and identified its main dimensions through literature review. As pointed out in literature review, trustworthiness and expertise are the focal dimensions of source credibility. Thus, to measure the source credibility of reviewers, it is essential to collect the data relevant to these dimensions.

\subsection{Crawling data from the web}

After identification of the key dimensions of source credibility, we crawled the required data from the web. As expressed before, as a case study, we selected the Epinions.com, which is a well-known product review website. Epinions is a large community network that enables users to share their knowledge and experiences about products and services. At Epinions.com, users can write reviews of products and services in various categories, for instance, in Electronics, Hardware and Software, Home and Garden, and so on. In addition, users can rate others' reviews with numerical rating $([1,5])$. The generated reviews can help consumers to make appropriate decisions in the process of purchasing a product or services. In Epinions, each user can explicitly express trust or distrust relationships to other users. Therefore, a Web Of Trust (WOT) [63,64] is established through a set of trust relationships.

In this study, we are interested in collecting the data of reviewers from the Electronics product category. In order to crawl the trust network of users, we started from the top reviewer in the product category "Electronics", followed both by the top reviewer's trusts and trusted by links to find other users. We used the breadth first search strategy to crawl the users'

$$
\begin{aligned}
& p\left(\tilde{\tilde{S}}_{i} \geq \tilde{\tilde{S}}_{j}\right)=\min (\max (Y, 0), 1) \\
& Y=\frac{\sum_{T \in\{L, U\}}\left(\left(s_{i 3}^{T}-s_{i 4}^{T}\right)-\left(s_{j 1}^{T}-s_{j 2}^{T}\right)\right)+\sum_{k=1}^{2}\left(\max \left(\left(H_{k}\left(\tilde{S}_{i}^{U}\right)-H_{k}\left(\tilde{S}_{j}^{U}\right)\right), 0\right)+\max \left(\left(H_{k}\left(\tilde{S}_{i}^{L}\right)-H_{k}\left(\tilde{S}_{j}^{L}\right)\right), 0\right)\right)}{\sum_{k=1}^{4} \operatorname{len}\left(v_{k}\right)+\sum_{k=1}^{2}\left|H_{k}\left(\tilde{S}_{i}^{U}\right)-H_{k}\left(\tilde{S}_{j}^{U}\right)\right|+\sum_{k=1}^{2} \mid H_{k}\left(\tilde{S}_{i}^{L}\right)-H_{k}\left(\tilde{S}_{j}{ }^{L}\right)},
\end{aligned}
$$


Table 2. Statistics of data crawled.

\begin{tabular}{lc}
\hline Description & Number of \\
\hline \#Users & 13419 \\
\# Trust relations & 475574 \\
\# Reviews during one year & 15312 \\
\hline
\end{tabular}

network. In this study, the crawler was implemented using Scrapy framework.

The crawled data falls into three categories: (1) data of the trust network among users (WOT); (2) data of users' profile; for example, the number of past reviews, the number of user visits, the length of activity, and the number of personal information items disclosed; and (3) data of written reviews (review metadata) including review written date, title, category, product rating, and helpfulness rating for the period of one year. The statistics of crawled data are given in Table 2 .

The crawled data should be preprocessed before entering into the next phase. According to the crawl results, a certain number of users had not written reviews during the period of one year. Therefore, these users were filtered out. Besides, some users did not contribute in Electronics category, so we eliminated them from our data.

\subsection{Deriving and constructing features}

After accomplishing the crawling stage, the required features were extracted and derived from the data based on the two chief dimensions of source credibility, including trustworthiness and expertise. According to what mentioned in the Literature Review Section, source trustworthiness and expertise are the two primary determinants of source credibility $[15,47]$. In the following, we portray the derived features corresponding to each dimension.

\subsubsection{Deriving and constructing features corresponding to the trustworthiness}

Trustworthiness is defined as the extent to which an information source is perceived as providing information that reflects the source's real opinions and attitudes regarding something $[15,65]$. Trustworthiness is usually described by terms such as well-intentioned, truthful, and unbiased [15]. Based on the data crawled from the website, several features relevant to the trustworthiness dimension can be derived. As pointed out before, in the website used as a case study, users can constitute a trust network, which is known as a web of trust in the literature, by explicitly expressing whom they trust. Therefore, a web of trust can be a strong source for inferring the extent of a user's trustworthiness.

To derive and compute features indicating a user's trustworthiness from the web of trust, we employed social network analysis to compute users' importance in the trust network. Many centrality measures have been devised to gauge the importance and popularity of a node in a social network. PageRank [66,67] is an effective and suitable algorithm to calculate importance of nodes in a social. In this paper, we use PageRank algorithm which was developed by Page, et al. [66] for rating web documents in web search. The idea of PageRank algorithm can be exploited to identify the most influential nodes in a social network [68]. More details about PageRank are demonstrated in Table 3.

The other two features indicate trustworthiness, including user visits and number of personal information derived from profile data of users (as seen in Table 3). The reason behind selecting User Visits feature as a representative of trustworthiness of a reviewer is that the large number of user visits indicates that many people have visited and read the user's reviews which in turn reflects that the user has written

Table 3. Description of features utilized to estimate trustworthiness.

\begin{tabular}{|c|c|}
\hline Feature & Description \\
\hline PageRank $\left(F_{11}\right)$ & $\begin{array}{l}\text { The PageRank of vertex } i, P R(i) \text { is computed as follows: } \\
P R(i)=c \sum_{j} \frac{P R(j)}{d_{j}}+1-c[67] . \\
\text { where } j \text { is the set of inbounding vertices of } i ; d_{j} \text { is the out-degree of node } j \text {; and } c \text { is the } \\
\text { "damping factor", } \\
\text { a constant between } 0 \text { and } 1 \text { the graph [67]. }\end{array}$ \\
\hline User visits $\left(F_{12}\right)$ & The number of visitors who have viewed the reviews written by the user. \\
\hline $\begin{array}{l}\text { Number of personal } \\
\text { information }\left(F_{13}\right)\end{array}$ & The number of personal information provided by a user about himself/herself. \\
\hline Recency $\left(F_{14}\right)$ & $\begin{array}{l}\text { The time elapsed since the last review was written by reviewer. In other words, } \\
\text { how long ago a reviewer wrote the last review. }\end{array}$ \\
\hline
\end{tabular}


more reliable and truthful reviews. In addition, number of personal information feature is selected as a proxy for the source credibility, and especially for the trustworthiness. According to $[69,70]$, revealing personal identity information by reviewer has a positive effect on the perceived credibility of online reviews and can facilitate the evaluation of the aspects of the reviewers. In other words, consumers trust those reviews more which were written by reviewers who disclosed their personal identity information. As a result, we take into account the number of personal information as a criterion for measuring the trustworthiness.

Recency, which is defined as the time elapsed since the last review was written by a reviewer, may be a cue for active participation or activeness of a reviewer which in turn indicates a reviewer trustworthiness. To derive the recency feature, we adopt the principle of RFM analysis [71]. RFM refers to Recency, Frequency, and Monetary value of a customer's transactional history. RFM variables are defined as:

- Recency: The time that has elapsed since the customer made his last purchase;

- Frequency: The total number of purchases that a customer has made within a designated period of time;

- Monetary value: The total amount of money spent by the customer within a designated period of time [72].
All of the features derived to estimate the trustworthiness are shown in Table 3.

\subsubsection{Deriving and constructing features corresponding to the expertise}

Expertise is the degree to which an information source is perceived as being able to know the truth or to present valid information $[15,65]$. It is often expressed by terms such as experienced, knowled geable, and competent [15]. Expertise is directly related to knowledge about the goods or services, and increases as related experience increases [73]. A great experience (e.g., length and depth) of a person in an area may be an indicator of his or her expertness [74]. Therefore, there is a close relation between expertise, knowledge, and experience. In [73], the authors used a number of destinations visited to measure expertise of a reviewer in TripAdvisor.

In this study, we computed the experience feature as the length of participation of the reviewer in the website. In addition, some features indicating the past activity and level of contribution of reviewer, including level of contribution in the specific domain, were employed to quantify the expertise of reviewers. Table 4 shows the features utilized to quantify the expertise dimension.

As mentioned before, expertise is closely related to knowledge, so here we compute the knowledge score of reviewers based on the number of reviews written

Table 4. Description of features utilized to estimate expertise.

\begin{tabular}{|c|c|}
\hline Feature & Description \\
\hline Experience $\left(F_{21}\right)$ & $\begin{array}{l}\text { The length of time since reviewer membership. In other words, } \\
\text { how long a reviewer involves sharing and exchanging opinions. }\end{array}$ \\
\hline Level of contribution $\left(F_{22}\right)$ & $\begin{array}{l}\text { The number of reviews written by a reviewer in all categories } \\
\text { during the period of one year. }\end{array}$ \\
\hline $\begin{array}{l}\text { Level of contribution in the } \\
\text { specific domain }\left(F_{23}\right)\end{array}$ & $\begin{array}{l}\text { Number of reviews written by a reviewer in } \\
\text { a specific category during the period of one year. }\end{array}$ \\
\hline General knowledge score $\left(F_{24}\right)$ & $\begin{array}{l}G K S(i)=\left(1-\frac{1}{n+1}\right) \frac{\sum_{R\left(u_{i}\right)} r_{j}}{n} \\
\text { where } n \text { is the number of reviews written by reviewer } u_{i} \\
\text { in all categories during the period of one year; } R\left(u_{i}\right) \text { is the } \\
\text { set of reviews written by reviewer in all categories during the period } \\
\text { of one year; and } r_{j} \text { is the helpfulness rating of a review } R_{j} \text {. }\end{array}$ \\
\hline Domain-specific knowledge score $\left(F_{25}\right)$ & $\begin{array}{l}D K S(i)=\left(1-\frac{1}{n+1}\right) \frac{\sum_{j \in R\left(u_{i}\right)} r_{j}}{n} \\
\text { where } n \text { is the number of reviews written by reviewer } \\
u_{i} \text { in a specific category during the period of one year; } R\left(u_{i}\right) \text { is the } \\
\text { set of reviews written by reviewer in a specific category during the period of } \\
\text { one year; and } r_{j} \text { is the helpfulness rating of a review } R_{j} .\end{array}$ \\
\hline
\end{tabular}


Table 5. Linguistic terms and their corresponding trapezoidal IT2FN.

\begin{tabular}{lcc}
\hline Verbal judgment & Trapezoidal IT2 FN & Reciprocal trapezoidal IT2 FN \\
\hline Extremely More Importance (EMI) & $(7,8,9,9 ; 1,1)$ & $(0.11,0.11,0.12,0.14 ; 1,1)$ \\
& $(7.2,8.2,8.8,9 ; 0.8,0.8)$ & $(0.11,0.11,0.12,0.13 ; 0.8,0.8)$ \\
Very Strong Important (VSI) & $(5,6,8,9 ; 1,1)$ & $(0.11,0.12,0.16,0.2 ; 1,1)$ \\
& $(5.2,6.2,7.8,8.8 ; 0.8,0.8)$ & $(0.11,0.12,0.16,0.19 ; 0.8,0.8)$ \\
Strong Important (SI) & $(3,4,6,7 ; 1,1)$ & $(0.14,0.16,0.25,0.33 ; 1,1)$ \\
& $(3.2,4.2,5.8,6.8 ; 0.8,0.8)$ & $(0.14,0.17,0.23,0.31 ; 0.8,0.8)$ \\
Moderate Important (MI) & $(1,2,4,5 ; 1,1)$ & $(0.2,0.25,0.5,1 ; 1,1)$ \\
& $(1.2,2.2,3.8,4.8 ; 0.8,0.8)$ & $(0.20,0.26,0.45,0.83 ; 0.8,0.8)$ \\
Equal Important (EI) & $(1,1,3,3 ; 1,1)$ & $(0.33,0.33,1,1 ; 1,1)$ \\
& $(1.2,1.2,2.8,2.8 ; 0.8,0.8)$ & $(0.36,0.36,0.83,0.83 ; 0.8,0.8)$ \\
Just equal & $(1,1,1,1 ; 1,1)$ & $(1,1,1,1 ; 1,1)$ \\
\hline
\end{tabular}

and overall satisfaction on reviews, which is calculated as the average of other users' ratings on a review written by the reviewer. Since each reviewer usually writes reviews on products and services from various categories, we estimate general knowledge and domainspecific knowledge scores for each reviewer. All the features derived to estimate the expertise dimension are described in Table 4.

\subsection{Weighting features using interval type-2 fuzzy $\boldsymbol{A H P}$}

So far, the features corresponding to the trustworthiness and expertise have been identified (Table 3). To determine the weights of features, the pairwise comparisons are accomplished. To perform pairwise comparison, we employ a set of linguistic terms. The linguistic terms are described by trapezoidal Interval Type-2 Fuzzy Numbers (IT2 FN) as shown in Table 5. For features corresponding to the both dimensions, we gathered the fuzzy pairwise comparison matrices through interviews. A series of questions were designed and used for direct comparison. The result of interviewing each expert is a fuzzy pairwise comparison matrix, which is indicating the expert's preferences regarding the features. In this study, we collected the opinions of five experts. After collecting the opinions of the experts, the IT2 FAHP method was applied to calculate weights of the features.

\subsubsection{Weights of trustworthiness features}

In this step, the IT2 FAHP method was employed to calculate the weights of features corresponding to the trustworthiness (Table 3). All matrices were
Table 6. Consistency index of the pairwise comparison matrix of each expert trustworthiness.

\begin{tabular}{cccccc}
\hline & E1 & E2 & E3 & E4 & E5 \\
\hline CR & 0.0796 & 0.0872 & 0.0872 & 0.0717 & 0.0872 \\
\hline
\end{tabular}

put through consistency check (Step 2). Using the proposed method DTITFN, the defuzzified pairwise comparison matrices were obtained. Each defuzzified pairwise comparison matrix for the features was checked for its consistency. As shown in Table 6, the matrices are consistent since $C R<0.1$. According to the third step of IT2 FAHP, we used Eq. (31) to combine the opinions of five experts as shown in Table 7. By applying Eq. (33), the values of fuzzy synthetic extent were calculated; the results are illustrated in Table 11.

By following Step 5 of the IT2 FAHP, a possibility degree matrix, $P_{t}$, was determined based on Eqs. (34)(36) as follows:

$$
P_{t}=\left(\begin{array}{cccc}
0.5 & 0.5959 & 1 & 1 \\
0.4041 & 0.5 & 1 & 1 \\
0 & 0 & 0.5 & 0.3117 \\
0 & 0 & 0.6883 & 0.5
\end{array}\right)
$$

Finally, by tracing Step 6 of the IT2 FAHP, the weight of each feature was computed using Eqs. (37) and (38) (as shown in Table 8). The global weights were attained by dividing the local weights by two.

\subsubsection{Weights of expertise feature}

Similar to the previous stage, the IT2 FAHP method was utilized in this stage to calculate the weights 
Table 7. Pairwise comparison of the features corresponding to the trustworthiness.

\begin{tabular}{|c|c|c|c|c|}
\hline & $F_{11}$ & $F_{12}$ & $F_{13}$ & $F_{14}$ \\
\hline \multirow{2}{*}{$F_{11}$} & $(1,1,1,1 ; 1,1)$ & $(0.8,0.8,2.41,2.41 ; 1,1)$ & $(4.36,5.4,7.3,8.14,1,1)$ & $(2.95,4.1,6.21,7.24,1,1)$ \\
\hline & $(1,1,1,1 ; 1,1)$ & $(0.94,0.94,2.2,2.2 ; 0.8,0.8)$ & $(4.57,5.61,7.1,7.97,0.8,0.8)$ & $(3.19,4.31,6,7.03,0.8,0.8)$ \\
\hline \multirow{2}{*}{$F_{12}$} & $(0.42,0.42,1.25,1.25 ; 1,1)$ & $(1,1,1,1 ; 1,1)$ & $(2.95,4.1,6.21,7.24 ; 1,1)$ & $(2.41,3.48,5.53,6.54 ; 1,1)$ \\
\hline & $(0.46,0.46,1.06,1.06 ; 0.8,0.8)$ & $(1,1,1,1 ; 1,1)$ & $(3.19,4.31,6,7.03 ; 0.8,0.8)$ & $(2.63,3.69,5.33,6.34 ; 0.8,0.8)$ \\
\hline \multirow{2}{*}{$F_{13}$} & $(0.12,0.14,0.19,0.23 ; 1,1)$ & $(0.14,0.16,0.24,0.34 ; 1,1)$ & $(1,1,1,1 ; 1,1)$ & $(0.42,0.42,1.25,1.25 ; 1,1)$ \\
\hline & $(0.13,0.14,0.18,0.22 ; 0.8,0.8)$ & $(0.14,0.17,0.23,0.31 ; 0.8,0.8)$ & $(1,1,1,1 ; 1,1)$ & $(0.46,0.46,1.06,1.06 ; 0.8,0.8)$ \\
\hline \multirow{2}{*}{$F_{14}$} & $(0.14,0.16,0.24,0.34 ; 1,1)$ & $(0.15,0.18,0.29,0.42 ; 1,1)$ & $(0.8,0.8,2.41,2.41 ; 1,1)$ & $(1,1,1,1 ; 1,1)$ \\
\hline & $(0.14,0.17,0.23,0.31 ; 0.8,0.8)$ & $(0.16,0.19,0.27,0.38 ; 0.8,0.8)$ & $(0.94,0.94,2.2,2.2 ; 0.8,0.8)$ & $(1,1,1,1 ; 1,1)$ \\
\hline
\end{tabular}

Table 8. The computed weights of features representing trustworthiness.

\begin{tabular}{cccc}
\hline Feature & $\boldsymbol{S}_{\boldsymbol{i}}$ & Local weight & Global weight \\
\hline PageRank $\left(F_{11}\right)$ & $(0.22,0.3,0.7,0.96 ; 1,1)$ & 0.4327 & 0.2163 \\
& $(0.24,0.33,0.64,0.87 ; 0.8,0.8)$ & & \\
User visits $\left(F_{12}\right)$ & $(0.16,0.24,0.58,0.82 ; 1,1)$ & 0.4007 & 0.2003 \\
& $(0.18,0.26,0.53,0.74 ; 0.8,0.8)$ & & \\
Personal information $\left(F_{13}\right)$ & $(0.04,0.05,0.11,0.14 ; 1,1)$ & 0.0260 \\
& $(0.04,0.05,0.1,0.12 ; 0.8,0.8)$ & & \\
Recency $\left(F_{14}\right)$ & $(0.05,0.06,0.16,0.21 ; 1,1)$ & & 0.1147 \\
& $(0.06,0.06,0.15,0.19 ; 0.8,0.8)$ & & 0.0574 \\
\hline
\end{tabular}

Table 9. Consistency index of the pairwise comparison matrix of each expert for expertise.

\begin{tabular}{cccccc}
\hline & E1 & E2 & E3 & E4 & E5 \\
\hline CR & 0.0935 & 0.0883 & 0.0974 & 0.0958 & 0.0597 \\
\hline
\end{tabular}

of features corresponding to the expertise dimension (Table 4). All matrices were put through consistency check (Step 2). Exploiting the proposed method DTITFN, the defuzzified pairwise comparison matrices were obtained. Each defuzzified pairwise comparison matrix for the features was examined for its consistency. As seen in Table 9, the matrices were consistent since $\mathrm{CR}<0.1$. After checking the consistency of fuzzy pairwise comparison matrices (Step 2), according to the third step of IT2 FAHP, opinions of five experts regarding the importance of expertise features were aggregated and presented in Table 10. By applying Eq. (33), the values of fuzzy synthetic extent were calculated, and the results are shown in Table 11.

By following Step 5 of the IT2 FAHP, a possibility degree matrix, $P_{e}$, was determined based on Eqs. (34),

Table 10. Pairwise comparison of the features corresponding to the expertise.

\begin{tabular}{|c|c|c|c|c|c|}
\hline & $\boldsymbol{F}_{21}$ & $F_{22}$ & $F_{23}$ & $F_{24}$ & $F_{25}$ \\
\hline \multirow{2}{*}{$F_{21}$} & $(1,1,1,1 ; 1,1)$ & $(0.34,0.37,0.94,1.25 ; 1,1)$ & $(0.12,0.13,0.16,0.19 ; 1,1)$ & $(0.37,0.39,1.08,1.25 ; 1,1)$ & $(0.12,0.13,0.16,0.19 ; 1,1)$ \\
\hline & $(1,1,1,1 ; 1,1)$ & $(0.37,0.4,0.83,1.06 ; 0.8,0.8)$ & $(0.12,0.13,0.16,0.19 ; 0.8,0.8)$ & $(0.41,0.43,0.94,1.06 ; 0.8,0.8)$ & $(0.12,0.13,0.16,0.19 ; 0.8,0.8)$ \\
\hline \multirow{2}{*}{$F_{22}$} & $(0.8,1.06,2.7,2.95 ; 1,1)$ & $(1,1,1,1 ; 1,1)$ & $(0.15,0.18,0.29,0.42 ; 1,1)$ & $(0.8,0.8,2.41,2.41 ; 1,1)$ & $(0.15,0.17,0.28,0.42 ; 1,1)$ \\
\hline & $(0.94,1.2,2.48,2.73,0.8,0.8)$ & $(1,1,1,1 ; 1,1)$ & $(0.16,0.19,0.27,0.38 ; 0.8,0.8)$ & $(0.94,0.94,2.2,2.2 ; 0.8,0.8)$ & $(0.15,0.18,0.26,0.38 ; 0.8,0.8)$ \\
\hline \multirow{2}{*}{$F_{23}$} & $(5.52,6.58,8.11,8.56 ; 1,1)$ & $(2.41,3.48,5.53,6.54 ; 1,1)$ & $(1,1,1,1 ; 1,1)$ & $(2.95,4.1,6.21,7.24 ; 1,1)$ & $(0.42,0.46,1.18,1.55 ; 1,1)$ \\
\hline & $(5.74,6.78,7.9,8.47 ; 0.8,0.8)$ & $(2.63,3.69,5.33,6.34 ; 0.8,0.8)$ & $(1,1,1,1 ; 1,1)$ & $(3.19,4.31,6,7.03 ; 0.8,0.8)$ & $(0.47,0.51,1.06,1.35 ; 0.8,0.8)$ \\
\hline \multirow{2}{*}{$F_{24}$} & $(0.8,0.92,2.55,2.67 ; 1,1)$ & $(0.42,0.42,1.25,1.25 ; 1,1)$ & $(0.14,0.16,0.24,0.34 ; 1,1)$ & $(1,1,1,1 ; 1,1)$ & $(0.13,0.15,0.21,0.27 ; 1,1)$ \\
\hline & $(0.94,1.06,2.34,2.45 ; 0.8,0.8)$ & $(0.46,0.46,1.06,1.06 ; 0.8,0.8)$ & $(0.14,0.17,0.23,0.31 ; 0.8,0.8)$ & $(1,1,1,1 ; 1,1)$ & $(0.13,0.15,0.2,0.26 ; 0.8,0.8)$ \\
\hline \multirow{2}{*}{$F_{25}$} & $(5.16,6.21,7.92,8.56 ; 1,1)$ & $(2.37,3.57,5.72,6.77 ; 1,1)$ & $(0.64,0.85,2.17,2.37 ; 1,1)$ & $(3.68,4.7,6.73,7.74 ; 1,1)$ & $(1,1,1,1 ; 1,1)$ \\
\hline & $(5.37,6.41,7.71,8.43 ; 0.8,0.8)$ & $(2.62,3.79,5.51,6.56 ; 0.8,0.8)$ & $(0.74,0.94,1.95,2.14 ; 0.8,0.8)$ & $(3.89,4.91,6.53,7.54 ; 0.8,0.8)$ & $(1,1,1,1 ; 1,1)$ \\
\hline
\end{tabular}


Table 11. The computed weights of features representing expertise.

\begin{tabular}{lccc}
\hline \multicolumn{1}{c}{ Feature } & $\boldsymbol{S}_{\boldsymbol{i}}$ & Local weight & Global weight \\
\hline Experience $\left(F_{21}\right)$ & $(0.03,0.03,0.08,0.12 ; 1,1)$ & 0.0533 & 0.0267 \\
& $(0.03,0.04,0.07,0.1 ; 0.8,0.8)$ & & 0.0691 \\
Level of contribution $\left(F_{22}\right)$ & $(0.04,0.05,0.17,0.22 ; 1,1)$ & 0.1381 & 0.1736 \\
& $(0.05,0.06,0.15,0.19 ; 0.8,0.8)$ & & 0.3471 \\
Level of contribution in the specific domain $\left(F_{23}\right)$ & $(0.18,0.26,0.55,0.77 ; 1,1)$ & & 0.0543 \\
& $(0.2,0.28,0.51,0.7 ; 0.8,0.8)$ & & 0.1085 \\
General knowledge score $\left(F_{24}\right)$ & $(0.04,0.04,0.13,0.17 ; 1,1)$ & 0.1764 \\
Domain knowledge score $\left(F_{25}\right)$ & $(0.04,0.05,0.12,0.15 ; 0.8,0.8)$ & & 0.3529 \\
\hline
\end{tabular}

Table 12. Comparison of Chang's Type-1 FAHP and IT2FAHP.

\begin{tabular}{|c|c|c|c|c|c|}
\hline \multirow[t]{2}{*}{ Feature } & & \multicolumn{2}{|c|}{ Chang's type-1 FAHP } & \multicolumn{2}{|c|}{ IT2 FAHP } \\
\hline & & Weight & Rank & Weight & Rank \\
\hline \multirow{4}{*}{ Trustworthiness } & $F_{11}$ & 0.2627 & 1 & 0.2163 & 1 \\
\hline & $F_{12}$ & 0.2373 & 2 & 0.2003 & 2 \\
\hline & $F_{13}$ & 0 & 3 & 0.0260 & 4 \\
\hline & $F_{14}$ & 0 & 3 & 0.0574 & 3 \\
\hline \multirow{5}{*}{ Expertise } & $F_{21}$ & 0 & 4 & 0.0267 & 5 \\
\hline & $F_{22}$ & 0.0220 & 3 & 0.0691 & 3 \\
\hline & $F_{23}$ & 0.2339 & 2 & 0.1736 & 2 \\
\hline & $F_{24}$ & 0 & 4 & 0.0543 & 4 \\
\hline & $F_{25}$ & 0.2441 & 1 & 0.1764 & 1 \\
\hline
\end{tabular}

(35) and (36) as follows:

$P_{e}=\left(\begin{array}{ccccc}0.5000 & 0.2208 & 0 & 0.3125 & 0 \\ 0.7792 & 0.5000 & 0 & 0.6022 & 0 \\ 1.0000 & 1.0000 & 0.5000 & 1.0000 & 0.7415 \\ 0.6875 & 0.3978 & 0 & 0.5000 & 0 \\ 1.0000 & 1.0000 & 0.5285 & 1.0000 & 0.5000\end{array}\right)$

Finally, by tracing Step 5 of the IT2 FAHP, the weight of each feature was computed using Eqs. (37) and (38) (as seen in Table 11). The global weights were obtained by dividing the local weights by two.

\subsection{Comparison of Chang's type-1 FAHP with the proposed method}

In order to compare our proposed method with Chang's type-1 FAHP [43] method, we employed type-1 FAHP to determinate the importance weights of the features describing the reviewers. The obtained results using both methods are illustrated in Table 12. As seen in the table, by employing type- 1 FAHP, the importance weights of $F_{13}$ and $F_{14}$ become zero. In addition, through applying type-1 FAHP, the importance weights of $F_{21}$ and $F_{24}$ are equal to zero. The reason for this result is that in Chang's type-1 FAHP, if a criterion is less important than all of the others, then relatively this criterion has no importance and its weight is zero. That is, type-1 FAHP allows "having zero weight" situation.

Looking at the results obtained by IT2FAHP, we notice that the "having zero weight" situation is avoided. In addition, both methods give the same ranking for the features having non-zero weights. For example, both methods have the same ranking for $F_{11}$, $F_{12}, F_{25}, F_{23}$, and $F_{22}$.

Considering the result of comparison of weights and ranking values between the IT2FAHP and type-1 FAHP, it can be concluded that the proposed IT2FAHP is promising and can handle fuzzy MCDM problems 
with a more comprehensible approach, as it uses a set of linguistic terms which is expressed in a more detailed and flexible way by trapezoidal interval tytpe-2 fuzzy sets.

\subsection{Ranking reviewers using TOPSIS}

Based on the TOPSIS method described in the Literature Review Section and the obtained weights of features employing the proposed IT2 FAHP method, we aim to rank reviewers whose data were crawled. According to what mentioned earlier, we formulate the problem of ranking reviewers as a multi-criteria decision making problem. Therefore, we consider quantitative features corresponding to the reviewer credibility derived from the gathered data as criteria. Consequently, for the problem with 220 reviewers and 9 features, we can formulate it as an MCDM problem with 220 alternatives and 9 criteria.

Using steps of TOPSIS portrayed in the literature review, here we are going to rank the reviewers. After accomplishing Steps 1 and 2, the weighted normalized decision matrix is obtained. Part of data of reviewers from the weighted normalized decision matrix is displayed in Table 13. Table 14 displays the result of Step 3 that computes the ideal and anti-ideal points. After completing Steps 4-6, reviewers are ranked. The results of ranking reviewers are illustrated Table 15 .
One of the ranking methods used by Epinions to rank reviewers is the popular author ranking method, which is calculated based on the total hits to user's reviews. Therefore, on Epinions, popular author ranking is performed using the total hits measure. Based on the features we have utilized in the proposed approach, it is clear that our approach is not limited to one measure, and it operates based on the source credibility dimensions studied in literature.

\subsection{Discussion}

Identification of credible reviewers is highly significant for both consumers and companies. Our presented methodology has some advantages. Firstly, it identifies credible reviewers based on the credibility dimensions that were acknowledged in the literature. Secondly, in the proposed framework, we exploit relevant and informative data to quantify the source credibility dimensions. To derive features corresponding to the credibility dimensions, we perform a comprehensive literature review and use techniques and concepts from the social network analysis domain. Finally, after deriving the features representing the reviewers, we employ our developed IT2 FAHP to determine the importance of each feature for effectively ranking reviewers.

Table 13. Part of weighted normalized decision matrix.

\begin{tabular}{cccccccccc}
\hline & $\boldsymbol{F}_{\mathbf{1 1}}$ & $\boldsymbol{F}_{\mathbf{1 2}}$ & $\boldsymbol{F}_{\mathbf{1 3}}$ & $\boldsymbol{F}_{\mathbf{1 4}}$ & $\boldsymbol{F}_{\mathbf{2 1}}$ & $\boldsymbol{F}_{\mathbf{2 2}}$ & $\boldsymbol{F}_{\mathbf{2 3}}$ & $\boldsymbol{F}_{\mathbf{2 4}}$ & $\boldsymbol{F}_{\mathbf{2 5}}$ \\
\hline $\boldsymbol{R}_{\mathbf{1}}$ & 0.0001 & 0 & 0.0013 & 0.0036 & 0.0001 & 0.0011 & 0.0099 & 0.0037 & 0.0123 \\
$\boldsymbol{R}_{\mathbf{2}}$ & 0.0001 & 0 & 0 & 0.0018 & 0.0001 & 0 & 0 & 0 & 0 \\
$\boldsymbol{R}_{\mathbf{3}}$ & 0 & 0 & 0.0013 & 0.0047 & 0 & 0.0008 & 0 & 0.004 & 0.0082 \\
$\boldsymbol{R}_{\mathbf{4}}$ & 0.0009 & 0.001 & 0 & 0.0004 & 0.0023 & 0.0001 & 0 & 0.0031 & 0.0109 \\
$\boldsymbol{R}_{\mathbf{5}}$ & 0.0161 & 0.0201 & 0.0025 & 0.0051 & 0.0022 & 0.0074 & 0.005 & 0.0046 & 0.0146 \\
$\boldsymbol{R}_{\mathbf{6}}$ & 0.0023 & 0.0006 & 0 & 0.0018 & 0.002 & 0.0006 & 0 & 0.0041 & 0.0109 \\
$\boldsymbol{R}_{\mathbf{7}}$ & 0 & 0 & 0 & 0.0023 & 0.0008 & 0 & 0 & 0.0023 & 0.0109 \\
$\boldsymbol{R}_{\mathbf{8}}$ & 0.0009 & 0 & 0.0025 & 0.0051 & 0.0001 & 0.0042 & 0 & 0.0046 & 0.0109 \\
$\boldsymbol{R}_{\mathbf{9}}$ & 0.0002 & 0 & 0.0013 & 0.0049 & 0.0002 & 0.0057 & 0.005 & 0.0046 & 0.0146 \\
$\boldsymbol{R}_{\mathbf{1 0}}$ & 0.0298 & 0.005 & 0.0025 & 0.003 & 0.0025 & 0.0023 & 0 & 0.0045 & 0.0109 \\
\hline
\end{tabular}

Table 14. Calculated $v^{+}$and $v^{-}$.

\begin{tabular}{cccccccccc}
\hline & $\boldsymbol{F}_{\mathbf{1 1}}$ & $\boldsymbol{F}_{\mathbf{1 2}}$ & $\boldsymbol{F}_{\mathbf{1 3}}$ & $\boldsymbol{F}_{\mathbf{1 4}}$ & $\boldsymbol{F}_{\mathbf{2 1}}$ & $\boldsymbol{F}_{\mathbf{2 2}}$ & $\boldsymbol{F}_{\mathbf{2 3}}$ & $\boldsymbol{F}_{\mathbf{2 4}}$ & $\boldsymbol{F}_{\mathbf{2 5}}$ \\
\hline $\boldsymbol{v}^{+}$ & 0.0937 & 0.0963 & 0.0038 & 0.0051 & 0.0026 & 0.041 & 0.1199 & 0.0046 & 0.021 \\
$\boldsymbol{v}^{-}$ & 0 & 0 & 0 & 0 & 0 & 0 & 0 & 0 & 0 \\
\hline
\end{tabular}

Table 15. The top 10 reviewers ranked using the proposed approach.

\begin{tabular}{cccccccccccc}
\hline & \multicolumn{10}{c}{ Rank } \\
\cline { 2 - 12 } Reviewer & 1 & 2 & 3 & 4 & 5 & 6 & 7 & 8 & 9 & 10 \\
\cline { 2 - 12 } & $R_{119}$ & $R_{95}$ & $R_{75}$ & $R_{103}$ & $R_{29}$ & $R_{57}$ & $R_{166}$ & $R_{94}$ & $R_{169}$ & $R_{38}$ \\
\hline
\end{tabular}




\subsubsection{Benefits of the proposed framework for consumers}

As mentioned earlier, in a product review website, reviewers can exchange their ideas and opinions about products and services in various categories. Although the generated reviews can be regarded as a key source for consumers in purchase decisions, especially in the evaluation of the experience goods, a large number of reviews, which vary greatly in quality, make it difficult for a consumer to recognize the credible reviewers and reviews. As a result, there is a need for a mechanism to automatically identify and rank credible reviewers to help consumers in finding informative and useful reviews. The proposed approach which makes use of several informative features corresponding to the source credibility dimensions can be a useful tool to rank reviewers, and consequently to assist consumers in finding helpful information.

\subsubsection{Benefits of the proposed framework for companies}

The proposed approach can bring many benefits, especially to the business enterprises. Due to the strict competition among firms in almost all industries, many firms are facing with the customer churn problem $[75,76]$, that is, customers decide to stop doing transactions with a typical firm and switch to another company in order to meet their needs. Therefore, firms are trying to understand their customers' opinions and sentiments regarding products and services offered by them using text mining, opinion mining tools, and techniques. In fact, the vital goal of opinion mining should aim to offer the professionals, like designers, a comprehensive view of customer experience and insights that provide important clues for designers to better understand the voice of the customer, and consequently, to improve their existing product offerings accordingly.

As expressed before, online product review platforms provide opportunities for firms to gather their customers feedbacks. However, as stressed in the past research [13], the quality of customer reviews varies greatly. So, to obtain the informative and high quality customer reviews, firms should concentrate on the most credible reviews. In addition, credibility assessment of source (reviewers) and message (reviews) are fundamentally and positively interdependent [15]. Therefore, the presented system can be exploited by the marketing department of a firm to find high-quality reviews contributed by credible reviewers. Due to the limited marketing resources in almost all firms, it is essential for firms to concentrate on the feedbacks and opinions of the most credible reviewers, i.e. experts and trustable reviewers. The proposed framework can be successfully employed by the marketing department of a firm to acquire accurate intelligence about customers' opinions on products and services in an efficient and effective manner, and improve its existing offerings accordingly.

\section{Conclusion}

This study propose a novel framework for ranking reviewers in terms of credibility in online communities based on interval type-2 fuzzy analytical hierarchy process and TOPSIS. The presented framework contains five main stages: identification of source credibility dimensions, data collection and preprocessing, construction of features, determination of the weights of features, and evaluation of the level of reviewers' credibility. To illustrate an application of the developed framework, we conducted an experimental study using real data crawled from Epinions. The contributions of this study are three-fold: First, the conventional mechanisms for ranking reviewers in online product review websites are based on the total hits to user's reviews. For example, on Epinions, popular author ranking is performed using the total hits measure. Based on the features we have utilized in the proposed approach, our approach is not limited to one measure and operates based on the source credibility dimensions studied in literature. Second, this study present a new fuzzy AHP method with trapezoidal interval type-2 fuzzy numbers for calculating weights of features used for ranking reviewers. The proposed IT2 FAHP can be applied to other applications. Third, the reviewers are ranked using TOPSIS. TOPSIS, significantly, can consider several features simultaneously in ranking reviewers in terms of credibility. The benefits of employing the developed method by a firm can be: (a) identification of the most credible reviewers and reviews in an efficient and effective manner; (b) gaining understanding towards customers' actual sentiments and attitudes regarding their offering by mining the most credible reviews; and (c) gaining business intelligence by understanding the real strengths and weaknesses of the firm through analyzing high-quality reviews and, thereby developing effective strategies to improve their products' standing.

\section{References}

1. O'Reilly, T. What Is Web 2.0, O'Reilly Media (2009).

2. Ghose, A. and Ipeirotis, P.G. "Estimating the helpfulness and economic impact of product reviews: Mining text and reviewer characteristics", IEEE Trans. on Knowl. and Data Eng., 23(10), pp. 1498-1512 (2011).

3. Yali, A. and Bayram, M. "eWom: The effects of online consumer reviews on purchasing decision of electronic goods", In Proceedings of the International Marketing Trends Conference, Venice (2010). 
4. Park, D.-H., Lee, J. and Han, I. "The effect of on-line consumer reviews on consumer purchasing intention: The moderating role of involvement", International Journal of Electronic Commerce, 11(4), pp. 125-148 (2007).

5. Mauri, A.G. and Minazzi, R. "Web reviews influence on expectations and purchasing intentions of hotel potential customers", International Journal of Hospitality Management, 34(0), pp. 99-107 (2013).

6. Qimin, C., Qiao, G., Yongliang, W. and Xianghua, W. "Text clustering using VSM with feature clusters", Neural Computing and Applications, pp. 1-9 (2014).

7. Moghaddam, S. and Ester, M. "Opinion digger: An unsupervised opinion miner from unstructured product reviews", In Proceedings of the 19th ACM International Conference on Information and Knowledge ManagementACM: Toronto, ON, Canada. pp. 18251828 (2010).

8. Chung, W. and Tseng, T.-L. "Discovering business intelligence from online product reviews: A ruleinduction framework", Expert Systems with Applications, 39(15), pp. 11870-11879 (2012).

9. Kaiser, C., Schlick, S. and Bodendorf, F. "Warning system for online market research - Identifying critical situations in online opinion formation", KnowledgeBased Systems, 24(6), pp. 824-836 (2011).

10. Khadjeh Nassirtoussi, A., Aghabozorgi, S., Ying Wah, T. and Ngo, D.C.L. "Text mining for market prediction: A systematic review", Expert Systems with Applications, 41(16), pp. 7653-7670 (2014).

11. Marrese-Taylor, E., Velásquez, J.D. and BravoMarquez, F. "A novel deterministic approach for aspect-based opinion mining in tourism products reviews", Expert Systems with Applications, 41(17), pp. 7764-7775 (2014).

12. Ku, Y.-C., Wei, C.-P. and Hsiao, H.-W. "To whom should I listen? Finding reputable reviewers in opinion-sharing communities", Decision Support Systems, 53(3), pp. 534-542 (2012).

13. Lu, Y., Tsaparas, P., Ntoulas, A. and Polanyi, L. "Exploiting social context for review quality prediction", In Proceedings of the 19th International Conference on World Wide WebACM: Raleigh, North Carolina, USA. pp. 691-700 (2010).

14. Liu, J., Cao, Y., Lin, C.-Y., Huang, Y. and Zhou, M. "Low-quality product review detection in opinion summarization", In Proceedings of the Joint Conference on Empirical Methods in Natural Language Processing and Computational Natural Language Learning EMNLP-CoNLL, pp. 334-342 (2007).

15. Wang, Y., Chan, S., Ngai, G. and Leong, H.-V. "Quantifying reviewer credibility in online tourism", In Database and Expert Systems Applications, H. Decker, et al., Editors, Springer Berlin Heidelber,. pp. 381-395 (2013).
16. Hwang, C.-L. and Yoon, K. "Methods for multiple attribute decision making", In Multiple Attribute Decision Making, Springer Berlin Heidelberg. pp. 58-191 (1981).

17. Tzeng, G.H. and Huang, J.J., Multiple Attribute Decision Making: Methods and Applications, Taylor \& Francis (2011).

18. Saaty, T.L., The Analytic Hierarchy Process: Planning, Priority Setting, Resource Allocation, McGrawHill (1980).

19. Keramati, A., Nazari-Shirkouhi, S., Moshki, H., Afshari-Mofrad, M. and Maleki-Berneti, E. "A novel methodology for evaluating the risk of CRM projects in fuzzy environment", Neural Computing and Applications, 23(1), pp. 29-53 (2013).

20. Mendel, J.M., John, R.I. and Feilong, L. "Interval type-2 fuzzy logic systems made simple", Fuzzy Systems, IEEE Transactions on, 14(6), pp. 808-821 (2006).

21. Castillo, O. and Melin, P., Type-2 Fuzzy Logic: Theory and Applications, Springer (2008).

22. Chen, S.-M. and Lee, L.-W. "Fuzzy multiple attributes group decision-making based on the interval type-2 TOPSIS method", Expert Systems with Applications, 37(4), pp. 2790-2798 (2010).

23. Chen, S.-M. and Lee, L.-W. "Fuzzy multiple attributes group decision-making based on the ranking values and the arithmetic operations of interval type-2 fuzzy sets", Expert Systems with Applications, 37(1), pp. 824-833 (2010).

24. Chen, S.-M., Yang, M.-W., Lee, L.-W. and Yang, S.W. "Fuzzy multiple attributes group decision-making based on ranking interval type-2 fuzzy sets", $E x$ pert Systems with Applications, 39(5), pp. 5295-5308 (2012).

25. Melin, P. and Castillo, O. "A review on type-2 fuzzy logic applications in clustering, classification and pattern recognition", Applied Soft Computing, 21(0), pp. 568-577 (2014).

26. Tavoosi, J. and Badamchizadeh, M. "A class of type-2 fuzzy neural networks for nonlinear dynamical system identification", Neural Computing and Applications, 23(3-4), pp. 707-717 (2013).

27. Li, C., Yi, J., Wang, M. and Zhang, G. "Monotonic type-2 fuzzy neural network and its application to thermal comfort prediction", Neural Computing and Applications, 23(7-8), pp. 1987-1998 (2013).

28. Dereli, T., Baykasoglu, A., Altun, K., Durmusoglu, A. and Türksen, I.B. "Industrial applications of type-2 fuzzy sets and systems: A concise review", Computers in Industry, 62(2), pp. 125-137 (2011).

29. Visconti, A. and Tahayori, H. "Artificial immune system based on interval type-2 fuzzy set paradigm", Applied Soft Computing, 11(6), pp. 4055-4063 (2011).

30. Dereli, T. and Altun, K. "Technology evaluation through the use of interval type-2 fuzzy sets and 
systems", Computers \& Industrial Engineering, 65(4), pp. 624-633 (2013).

31. Dereli, T. and Altun, K. "A novel approach for assessment of candidate technologies with respect to their innovation potentials: Quick innovation intelligence process", Expert Systems with Applications, 40(3), pp. 881-891 (2013).

32. Qin, J. and Liu, X. "Multi-attribute group decision making using combined ranking value under interval type-2 fuzzy environment", Information Sciences, 297(0), pp. 293-315 (2015).

33. Fazel Zarandi, M.H. and Gamasaee, R. "A type-2 fuzzy system model for reducing bullwhip effects in supply chains and its application in steel manufacturing", Scientia Iranica, 20(3), pp. 879-899 (2013).

34. Melin, P. and Castillo, O. "A new method for adaptive model-based control of non-linear plants using type-2 fuzzy logic and neural networks", In Fuzzy Systems, FUZZ '03 The 12th IEEE International Conference on (2003).

35. Hsiao, M.-Y., Li, T.-H.S., Lee, J.-Z., Chao, C.-H. and Tsai, S.-H. "Design of interval type-2 fuzzy slidingmode controller", Information Sciences, 178(6), pp. 1696-1716 (2008).

36. Yu, W.-S. and Chen, H.-S. "Interval type-2 fuzzy adaptive tracking control design for PMDC motor with the sector dead-zones", Information Sciences, 288(0), pp. 108-134 (2014).

37. Hosseini, R., Dehmeshki, J., Barman, S., Mazinani, M. and Qanadli, S. "A genetic type-2 fuzzy logic system for pattern recognition in computer aided detection systems", In Fuzzy Systems (FUZZ), IEEE International Conference on: IEEE (2010).

38. Sharma, P. and Bajaj, P. "Accuracy comparison of vehicle classification system using interval type-2 fuzzy inference system", In Emerging Trends in Engineering and Technology (ICETET), 2010 3rd International Conference on: IEEE (2010).

39. Saaty, T.L. and Peniwati, K., Group Decision Making: Drawing Out and Reconciling Differences, RWS Publications (2013).

40. Saaty, T.L. and Vargas, L.G., Models, Methods, Concepts \& Applications of the Analytic Hierarchy Process, Springer(2012).

41. Dağdeviren, M. and Yüksel, İ. "Developing a fuzzy analytic hierarchy process (AHP) model for behaviorbased safety management", Information Sciences, 178(6), pp. 1717-1733 (2008).

42. Demirel, T., Demirel, N. and Kahraman, C. "Fuzzy analytic hierarchy process and its application", In Fuzzy Multi-Criteria Decision Making, C. Kahraman, Editor, Springer, U.S., pp. 53-83 (2008).

43. Chang, D.-Y. "Applications of the extent analysis method on fuzzy AHP", European Journal of Operational Research, 95(3), pp. 649-655 (1996).
44. Shahhosseini, V. and Sebt, M.H. "Competency-based selection and assignment of human resources to construction projects", Scientia Iranica, 18(2), pp. 163180 (2011).

45. Mikaeil, R., Yousefi, R. and Ataei, M. "Sawability ranking of carbonate rock using fuzzy analytical hierarchy process and TOPSIS approaches", Scientia Iranica, 18(5), pp. 1106-1115 (2011).

46. Hu, J., Zhang, Y., Chen, X. and Liu, Y. "Multi-criteria decision making method based on possibility degree of interval type-2 fuzzy number", Knowledge-Based Systems, 43, pp. 21-29 (2013).

47. Flanagin, A.J. and Metzger, M.J., Digital Media and Youth: Unparalleled Opportunity and Unprecedented Responsibility, In Digital Media, Youth, and Credibility, M.J. Metzger and A.J. Flanagin., Editors, The MIT Press: Cambridge, MA. pp. 5-28 (2008).

48. Tan, W.-K. and Chang, Y.-C. "Credibility Assessment Model of Travel Information Sources: An Exploratory Study on Travel Blogs", In Information and Communication Technologies in Tourism 2011, R. Law, M. Fuchs, and F. Ricci, Editors, Springer, Vienna, pp. 457-469 (2011).

49. Abbasi, M.-A. and Liu, H. "Measuring user credibility in social media", In Social Computing, BehavioralCultural Modeling and Prediction, A. Greenberg, W. Kennedy, and N. Bos, Editors, Springer Berlin Heidelberg, pp. 441-448 (2013).

50. Zadeh, L.A. "The concept of a linguistic variable and its application to approximate reasoning", Information Sciences, 8(3), pp. 199-249 (1975).

51. Kahraman, C., Fuzzy Multi-Criteria Decision Making: Theory and Applications with Recent Developments, Springer (2008).

52. Dereli, R., Baykasoglu, A., Altun, K., Durmusoglu, A. and Trksen, I.B. "Review: Industrial applications of type-2 fuzzy sets and systems: A concise review", Comput. Ind., 62(2), pp. 125-137 (2011).

53. Lee, L.-W. and Chen, S.-M. "A new method for fuzzy multiple attributes group decision-making based on the arithmetic operations of interval type-2 fuzzy sets", In International Conference on Machine Learning and Cybernetics (2008).

54. Ucal Sari, I. and Kahraman, C. "Interval type-2 fuzzy capital budgeting", International Journal of Fuzzy Systems, pp. 1-12 (2015).

55. Cevik Onar, S., Oztaysi, B. and Kahraman, C. "Strategic decision selection using hesitant fuzzy TOPSIS and interval type-2 fuzzy AHP: a case study", International Journal of Computational Intelligence Systems, 7(5), pp. 1002-1021 (2014).

56. Kannan, D., Jabbour, A.B.L.dDS. and Jabbour, C.J.C. "Selecting green suppliers based on GSCM practices: Using fuzzy TOPSIS applied to a Brazilian electronics company", European Journal of Operational Research, 233(2), pp. 432-447 (2014). 
57. Mandic, K., Delibasic, B., Knezevic, S. and Benkovic, S. "Analysis of the financial parameters of Serbian banks through the application of the fuzzy AHP and TOPSIS methods", Economic Modelling, 43(0), pp. 30-37 (2014).

58. Avikal, S., Jain, R. and Mishra, P.K. "A Kano model, AHP and M-TOPSIS method-based technique for disassembly line balancing under fuzzy environment", Applied Soft Computing, 25(0), pp. 519-529 (2014).

59. Sang, X., Liu, X. and Qin, J. "An analytical solution to fuzzy TOPSIS and its application in personnel selection for knowledge-intensive enterprise", Applied Soft Computing, 30(0), pp. 190-204 (2015).

60. Buckley, J.J. "Fuzzy hierarchical analysis", Fuzzy Sets and Systems, 17(3), pp. 233-247 (1985).

61. Chen, S.-H. and Hsieh, C.-H. "Graded mean representation of generalized fuzzy numbers", Proceeding of Conference on Fuzzy Theory and Its Applications (1998).

62. Xu, Z. "A ranking arithmetic for fuzzy mutual complementary judgment matrices", Journal of Systems Engineering, 16(4), pp. 311-314 (2001).

63. Kim, Y.A. and Phalak, R. "A trust prediction framework in rating-based experience sharing social networks without a web of trust", Information Sciences, 191(0), pp. 128-145 (2012).

64. Abbasimehr, H. and Tarokh, M. "Trust prediction in online communities employing neurofuzzy approach", Applied Artificial Intelligence, 29(7), pp. 733-751 (2015).

65. Cho, J., Kwon, K. and Park, Y. "Q-rater: A collaborative reputation system based on source credibility theory", Expert Systems with Applications, 36(2, Part 2), pp. 3751-3760 (2009).

66. Page, L., Brin, S., Motwani, R. and Winograd, T., The PageRank Citation Ranking: Bringing Order to the Web, Stanford InfoLab (1999).

67. Xu, G., Zhang, Y. and Li, L., Web Mining and Social Networking: Techniques and Applications, SpringerVerlag, New York, Inc. 210 (2010).

68. Aggarwal, C.C., Social Network Data Analytics, New York, USA: Springer (2011).

69. Xie, H., Miao, L., Kuo, P.-J. and Lee, B.-Y. "Consumers' responses to ambivalent online hotel reviews: The role of perceived source credibility and predecisional disposition", International Journal of Hospitality Management, 30(1), pp. 178-183 (2011).

70. Park, H., Xiang, Z., Josiam, B. and Kim, H. "Personal Profile Information as Cues of Credibility in Online Travel Reviews", In Information and Communication Technologies in Tourism, L. Cantoni and Z. Xiang, Editors, Springer, Berlin, Heidelberg, pp. 230-241 (2013).

71. Hughes, A., Strategic Database Marketing: The Masterplan for Starting and Managing a Profitable, Customer-Based Marketing Program, 4 Ed., McGrawHill Companies, Incorporated (2011).
72. Parvaneh, A., Tarokh, M. and Abbasimehr, H. "Combining data mining and group decision making in retailer segmentation based on LRFMP variables", $J$. Ind. Eng. Prod. Res., 25(3), pp. 197-206 (2014).

73. Lee, H.A., Law, R. and Murphy, J. "Helpful reviewers in TripAdvisor, an online travel community", Journal of Travel \& Tourism Marketing, 28(7), pp. 675-688 (2011).

74. Shanteau, J., Weiss, D.J., Thomas, R.P. and Pounds, J.C. "Performance-based assessment of expertise: How to decide if someone is an expert or not", European Journal of Operational Research, 136(2), pp. 253-263 (2002).

75. Abbasimehr, H., Setak, M. and Soroor, J. "A framework for identification of high-value customers by including social network based variables for churn prediction using neuro-fuzzy techniques", International Journal of Production Research, 51(4), pp. 1279-1294 (2013).

76. Verbeke, W., Dejaeger, K., Martens, D., Hur, J. and Baesens, B. "New insights into churn prediction in the telecommunication sector: A profit driven data mining approach", European Journal of Operational Research, 218(1), pp. 211-229 (2012).

\section{Biographies}

Hossein Abbasimehr received his BSc degree in Information Technology Engineering from Azarbaijan Shahid Madani University, Tabriz, Iran, in 2009, and his MSc degree in e-commerce from K. N. Toosi University of Technology, Tehran, Iran, in 2011. Currently, he is pursuing a PhD degree in Information Technology Engineering at K. N. Toosi University of Technology, Tehran, Iran. His research interests mainly include data mining, text mining, business intelligence, and customer relationship management.

Mohammad Jafar Tarokh is an Associate Professor in Industrial Engineering Department, K. N. Toosi University of Technology, Tehran, Iran. He received his BSc degree in applied mathematics in 1985 from Sharif University of Technology, Tehran, Iran; his MS degree in 1989 in Computer Science from Dundee University, $\mathrm{UK}$; and his PhD degree in Computer Application in Industrial Engineering from Bradford University, UK, 1993. His research interests are the analytical modeling of economics of information systems, business intelligence, competitive intelligence, strategic intelligence, and the impact of IT on firm strategies. His teaching interests include modeling and evaluation of computer system, supply chain management, customer relationship management, information technology, queuing systems, and extended enterprise. 